

\section{DISCLAIMER}

This report was prepared as an account of work sponsored by an agency of the United States Government. Neither the United States Government nor any agency Thereof, nor any of their employees, makes any warranty, express or implied, or assumes any legal liability or responsibility for the accuracy, completeness, or usefulness of any information, apparatus, product, or process disclosed, or represents that its use would not infringe privately owned rights. Reference herein to any specific commercial product, process, or service by trade name, trademark, manufacturer, or otherwise does not necessarily constitute or imply its endorsement, recommendation, or favoring by the United States Government or any agency thereof. The views and opinions of authors expressed herein do not necessarily state or reflect those of the United States Government or any agency thereof. 


\section{DISCLAIMER}

Portions of this document may be illegible in electronic image products. Images are produced from the best available original document. 


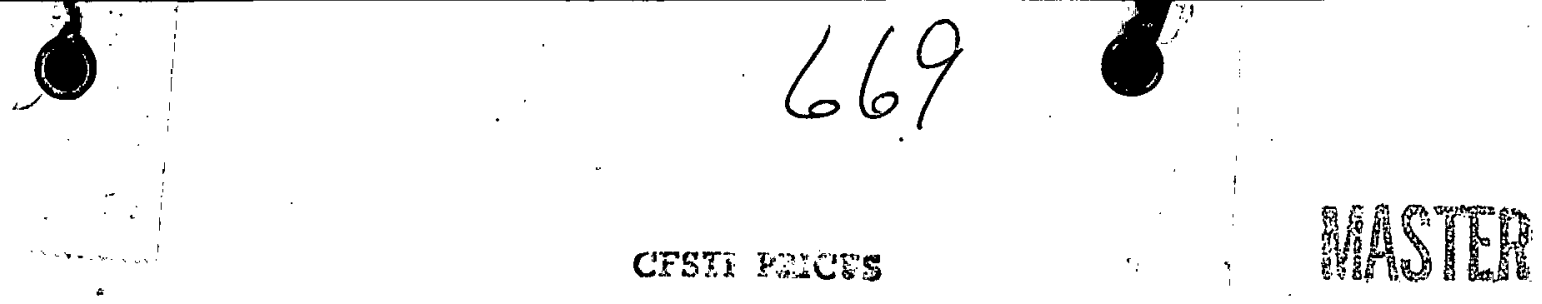

$\mathrm{sec}, 3,00 ; \mathrm{min} \cdot 65$ COO-1183-20

\author{
ANNUAL REPORT TO THE UNITED STATES
}

ATOMIC ENERGY COMMISSION

January 15, 1966 - April 30, 1967

Contract No.:

Contractor:
At $(11-1) 1183$

Continental Can Company, Inc.

Metal Division Research \& Development

1350 West 76 th Street

Chicago, Illinols 60620

\title{
Title: Growth Characteristics of Type E Clostridium botulinum in the Temperature Range 34 to $50 \mathrm{~F}$.
}

Apr11 30, 1967 
TABLE OF CONTENTS

Page

Summary

3

$\begin{array}{ll}\text { Introduction } & 14\end{array}$

Phase I.

Preparation and Standardization of

Spore Suspensions.

Phase V.

Outgrowth of Type E Spore Inocula

19

in Selected Marine Substrates.

Phase VII.

Toxin Assay Procedures.

24

Phase XIII.

Radiation Resistance of Spores of

39

Type $E$ in Phosphate Buffer and

Marine Homogenates in Relation to

Incubation Temperature.

Phase XVI,

Radiation Resistance of Spores from

Radiation Survivors.

Phase XVII

Toxin Development in Fresh Marine

Products .

General Discussion

References 
SUMMARY

Phase I

1. Previous efforts to produce spore crops at lower incubation temperatures $(60,50$ and $46 \mathrm{~F})$ had been unsuccessful due to to poor sporulation in TPG medium at these temperatures. In a comparative test with four strains in screw cap tubes containing either TPG or TPG plus $1 \%$ yeast extract, the refractile spore yields at $60 \mathrm{~F}$ and $50 \mathrm{~F}$ were increased 2-4 times. One small spore crop of the Beluga strain was produced in screw cap bottles of TPG medium plus 1\% Yeäst Extract with screw caps tight. Also at $46 \mathrm{~F}$ small lots of spore suspensions of the Beluga and Minneapolis strains were produced with moderate yields in bottles of TPG + Yeast Extract with tight screw caps. In a further attempt to produce a spore suspension at $50 \mathrm{~F}$ with tight caps on screw cap bottles one bottle burst due to pressure. Thereafter, bottles were incubated with the screw caps loose and although good vegetative growth occurred the percentage of sporulation was markedly reduced. In a further comparison of bottles with loose screw caps and a one 1 tter flask containing $200 \mathrm{ml}$ of medium layered with vaspar, the refractile spore yield in the bottles were $16-20 \times 10^{6} / \mathrm{ml}$ while that in the flask was $40 \times 10^{6} \mathrm{ml}$. Since bottles with tight screw caps should not be used due to the danger of bursting, it appears that the optimum method at present for production of spore crops at low temperatures is with the use of a vaspar seal. 
Phase V

1. Unheated and mildly preheated spore inocula of the Beluga, 8E, Alaska, and Minneapolis strains at an equivalent Inoculum level showed about the same outgrowth times. Also, with efther 0.1 or 0.2 Mrad irradiation, unheated and preheated spores gave practically the same outgrowth times.

2. The time of earliest Type $E$ toxin production in ground unsteamed haddock and cod substrates with anaerobic Incubation at 46,42 , and $40 \mathrm{~F}$ was determined without and with 0.1 and 0.2 Mrad irradiation. At an inoculum of $10^{6}$ spores/gm irradiated samples showed little extension of the toxin outbreak time over unirradiated samples. However, at an inoculum of $10^{4}$ spores/gm, irradiated samples showed no toxin after long incubation periods. No toxin was detected in irradiated haddock samples at 42 and $40 \mathrm{~F}$ after approximately two months of incubation. In cod, toxin was absent after 40 days at $40 \mathrm{~F}$ both with and without irradiations. These were the longest incubation times tested. At $46 \mathrm{~F}$, Irradiated haddock and cod showed a considerably longer toxin outbreak time than comparable inoculated unirradiated product.

3. The bacterial flora which survived 0.1 and 0.2 Mrad irradiation and grew anaerobifcally at temperatures of 46,42 , and $40 \mathrm{~F}$ appeared to consist only of Gram positive organisms. About

$$
-4-
$$


$70 \%$ of 100 1solates examined were catalase positive rodshaped bacteria.

4. The low temperature outgrowth ability of spores of the Beluga strain produced in Trypticase-Peptone-glucose medium plus $1.0 \%$ yeast extract with incubation at 46 and $50 \mathrm{~F}$ was studied. In comparison to spores of this strain produced at $85 \mathrm{~F}$, the low temperature spores inoculated Into steamed ground haddock showed somewhat faster outgrowth times with incubation at 40 and $38 \mathrm{~F}$. 
1. A considerable number of fish homogenate which were nontoxic by the conventional phosphate buffer procedure, showed Type E toxin when they were reassayed undigested and by a new procedure using a sodium acetate buffer system. The sodium acetate procedure like the phosphate buffer test involves trypsin digestion of the sample, but at a lower $\mathrm{pH}$ and for a longer time at $98 \mathrm{~F}(37 \mathrm{C})$.

2. Nonspecific toxicities frequently were encountered in mice inoculated intraperitoneally with fish samples undergoing decomposition. The earliest appearance of these nonspecific toxicities was longer with decreasing temperatures of product incubation and with 0.1 Mrad Irradiation in comparison to unirradiated product. No nonspecific toxicities were seen in product irradiated with 0.2 Mrad.

3. Blood cultures taken from mice showing nonspecific symptoms Indicated the cause was due to a massive septicemia. The organisms isolated belonged to the genera Proteus, Alcaligenes, Aerobacter, Actinobacillus, Enterococc1, and Erysipelothrix: Some of these isolates may represent secondary Invaders, since their apparent infectivity was low. Four isolates identified as E. Insidosa produced nonspectific symptoms and death of Inoculated mice and had a somewhat higher degree of infectivity as compared to the other isolates. 
4. The problem of nonspecific deaths in assays of fish samples for Type $E$ toxin was solved by the protection of mice with antibiotics. The intraperitoneal injection of Chloramphentcol and Terramycin protected mice from nonspecific symptoms for at least 48 hours and in most instances up to 4 days. 


\section{Phase XIII}

1. 'The resistance of spores of the Beluga strain to Co 60 Irradiation In TPG medium closely parellels that in haddock homogenate. 
1. The effect of repeated 0.8 Mrad radiation of spores of the Beluga strain was determined. Spores produced from the first, second, and third generation irradiation survivors showed about the same resistance to $\mathrm{Co}^{60}$ as spores of the parent suspension in terms of D-values.

2. Spores produced form the third generation $0.8 \mathrm{Mrad}$ survivors falled to give a survivor curve which exhibited a. "shoulder". Spores of the preceding suspensions including those of the parent suspension gave survivor curves with "shoulders" extending from 0.31 to $0.46 \mathrm{Mrad}$.

3. Spores of the third and fourth generation suspensions showed a reduction in viable count when inoculated into prechilled TPG medium and held at 34 F for about 24 hours. The low counts indicated spore germination and a loss in spore viability had occurred. This rapid germination at a temperature not permitting active growth suggested that spores of the fourth generation suspension might show faster outgrowth and toxin outbreak times at low temperatures than spores of the parent suspension. However, when spores of the fourth generation suspension were inoculated into steamed ground haddock, longer outgrowth times were recorded with Incubation at 42 and $40 \mathrm{~F}$. The results indicate that while spores of $\mathrm{C} 1$. botulinum Type $\mathrm{E}$ subjected to repeated $0.8 \mathrm{Mrad}$ 
radiation may germinate rapidly at low temperatures, they are not necessarily capable of active growth and toxin production to the same extent as those which have never been Irradiated. 
Phase XVII

1. Experiments have been conducted in fresh haddock (shipped iced from the Gloucester BCF laboratory) using the far method to determine the relationship between time for toxin development and maximum storage 11 fe. The procedures were those recommended by the Ad Hoc Committee on $\mathrm{Cl}$. botulinum. Maximum storage life is defined as the storage time for complete rejection by an untrained panel based on odor. The maximum storage 1ife of haddock fillets was determined by the Gloucester BCF laboratory. In these experiments, portions of fresh haddock fillets were packed in jars, inoculated with $10^{6}, 10^{4}$, or $10^{2}$ spores per gram, and following Irradiation of $0,0.1$ and 0.2 Mr stored at various temperatures. Toxin assays were conducted at time intervals corresponding to fractions or multiples of $X$ the maximum storage life for each variable. The $10^{6}$ inoculum was preheated for $15 \mathrm{~min}$ at $140 \mathrm{~F}$ to eliminate possible toxin carryover; the lower inoculum levels were used without preheat.

2. Using spores; of the Beluga strain produced at $85 \mathrm{~F}$ and on inoculum of $10^{4}$ or $10^{2} / \mathrm{gm}$, unirradiated samples at $50 \mathrm{~F}$ showed no toxin at 16 days $(2 \mathrm{X})$. With $10^{4}$ spores/gm and $0.1 \mathrm{Mr}$ no toxin was found after 24 days (2X) although at $0.2 \mathrm{Mr}$ toxin was found at 10 , 20 , and 40 days $(1 / 2 \mathrm{X}, \mathrm{X}$, and $2 \mathrm{X})$. With $0.1 \mathrm{Mr}$ no toxin was found after 6 and 12 days $(1 / 2 x, x)$, but was apparent after 24 
days (2X) in one of 3 replicate samples. Following $0.2 \mathrm{Mr}$ irradiation no toxin was evident at 10 days $(1 / 2 \mathrm{x})$, but was found after 20 and 40 days $(X, 2 X)$.

3. Using spores of the Beluga strain produced at $85 \mathrm{~F}$ and an inoculum level of $10^{6}$ or $10^{4}$ spores, unirradiated samples at $46 \mathrm{~F}$ showed no toxin at 24 days $(2 x)$. With an inoculum level of $10^{6}$ spores and $0.1 \mathrm{Mr}$ no toxin was found after 6,13 and 26 days $(1 / 2 \mathrm{x}, \mathrm{X}$ and $2 \mathrm{X}$ )... After $0.2 \mathrm{Mr}$ irradiation of $10^{6}$ spores, no toxin was found at 12 days $(1 / 2 x)$, but toxin was found after 24 and 50 days $(X, 2 X)$. At an inoculum level of $10^{4}$ spores/gm and storage at $46 \mathrm{~F}$ no toxin was found with $0.1 \mathrm{Mr}$ after 6,13 and 26 days $(1 / 2 \mathrm{X}, \mathrm{X}, 2 \mathrm{X})$ or with $0.2 \mathrm{Mr}$ after 12,24 and 50 days $(1 / 2 \mathrm{X}$, $\mathrm{x}, 2 \mathrm{x})$.

4. Using spores of the Beluga strain produced at $85 \mathrm{~F}$ inoculated at $10^{6}$ or $10^{4}$ per gram, in unirradiated samples stored at $40 \mathrm{~F}$ no toxin was found after $8,11,17,24$ or 34 days $(1 / 2 \mathrm{X}, 3 / 4 \mathrm{X}, \mathrm{X}, 11 / 2 \mathrm{X}, 2 \mathrm{X})$. Unirradiated samples stored at $42 \mathrm{~F}$ showed no toxin after $8,11,15,22$ and 29 days $(1 / 2 \mathrm{X}, 3 / 4 \mathrm{X}, \mathrm{X}, 11 / 2 \mathrm{X}, 2 \mathrm{X})$. Following $0.1 \mathrm{Mr}$, samples stored at $40 \mathrm{~F}$ showed no toxin after 19, 28, 39,60 and 82 days $(1 / 2 x, 3 / 4 X, X, 11 / 2 x, 2 X)$. Samples stored at $42 \mathrm{~F}$ after $0.1 \mathrm{Mr}$ 1rradiation showed no toxin after 14,22 , 29,46 or 60 days $(1 / 2 x, 3 / 4 x, x, 11 / 2 x, 2 x)$. Following $0.2 \mathrm{Mr}$ irradiation and storage at $40 \mathrm{~F}$ no toxin has been found 
after $20,29,40,60$ and 82 days $(1 / 2 x, 3 / 4 x, x, 11 / 2 x, 2 x)$. At $42 \mathrm{~F}$ after $0.2 \mathrm{Mr}$ samples stored for $18,27,36,54$ and 82 days $(1 / 2 x, 3 / 4 x, x, 11 / 2 x$ and $2 x)$ showed no measureable toxin production.

5. Using spores of the Beluga strain produced at $50 \mathrm{~F}$ inoculated at $10^{6}$ or $10^{4}$ per gram, unirradiated samples stored at $40 \mathrm{~F}$ showed no toxin after $9,16,26$ and 34 days $(3 / 4 \mathrm{X}, \mathrm{X}, 1 \mathrm{1} / 2 \mathrm{X}$, 2X). Unirradiated samples stored at $42 \mathrm{~F}$ were nontoxic after $9,15,21$ and 30 days $(3 / 4 \mathrm{X}, \mathrm{X}, 11 / 2 \mathrm{X}, 2 \mathrm{X})$. Following $1 \mathrm{r}-$ radiation at $0.1 \mathrm{Mr}$ no toxin was found after $31,39,60$ and 80 days $(3 / 4 \mathrm{X}, \mathrm{X}, 11 / 2 \mathrm{X} 2 \mathrm{X})$ storage at $40 \mathrm{~F}$, or after 21,31 , 45 and 60 days $(3 / 4 X, X, 11 / 2 X, 2 X)$ storage at $42 F$. Following Irradiation at $0.2 \mathrm{Mr}$, no toxin was found after $31,40,60$ and 80 days $(3 / 4 \mathrm{X}, \mathrm{X}, 11 / 2 \mathrm{X}, 2 \mathrm{X})$ storage at $40 \mathrm{~F}$ or after $27,35,55$ and 72 days $(3 / 4 \mathrm{X}, \mathrm{X}, 11 / 2 \mathrm{X}, 2 \mathrm{X})$ storage at $42 \mathrm{~F}$. 
INTRODUCTION

The use of ionizing radiation for the preservation of food products is a totally new concept that appears to have considerable potential. In contrast to sterilizing doses (minimum 4.5 Mrad), the United States Atomic Energy Commission has proposed the application of substerilizing doses, so called pasteurizing doses (generally below 1.0 Mrad), for the shelf life extension of certain selected food products. Among the items that appears promising are refrigerated fresh marine products, because of their extreme perishability. However, a marked extension of the refrigerated storage life of irradiated marine products might create a possible health problem due to Clostridium botulinum Type E. The possible health hazard risk of $\mathrm{Cl}$. botulinum Type $\mathrm{E}$ in irradiated marine products is based upon the ubiquity of its spores in nature, the resistance of its spores to radiation, and its ability to grow and produce toxin in the refrigeration temperature zone. Work was initiated in 1962 under contract AT (11-1) 1183 in this laboratory to determine the factors that influence the outgrowth of spores and toxin production of Cl. botulinum Type $\mathrm{E}$ in marine products at $50 \mathrm{~F}$ and below. This report summarizes work conducted from January 15, 1966 to April 30, 1967 in the following areas of investigation:

Phase I. Preparation and Standardization of Spore Suspensions.

Phase V. Outgrowth of Type E Spore Inocula in Selected Marine Substrates. 
Phase VII. Toxin Assay Procedures.

Phase XIII Radiation Resistance of Spores of Type E in Phosphate Buffer and Marine Homogenates in Relation to incubation temperature.

Phase XVI Radiation Resistance of Spores Produced from Radiation Survivors.

Phase XVII Toxin Development in Fresh Marine Products. 


\section{Phase I}

PREPARATION AND STANDARDIZATION OF SPORE SUSPENSIONS

In previous work in this and other laboratories, the spore crops used for the determination of the outgrowth properties of Type $E$ spores at low temperature have been produced in TPG medium at $85 \mathrm{~F}$. As we have pointed out in previous Annual Reports it would appear desirable to determine the outgrowth characteristics of spores produced at lower temperatures since this may more nearly resemble the conditions for the formation of the spores in nature. The main obstacle in this endeavor has been the low spore yield at $60 \mathrm{~F}$ and below in TPG medium.

Using $20 \times 150 \mathrm{~mm}$ screw cap tubes containing $20 \mathrm{ml}$ of medium a comparison was made of sporulation of four strains in TPG medium and TPG medium containing $1 \%$ yeast extract. These tubes were incubated with the screw caps tight and inverted daily as soon as evidence of growth occurred. Sets of tubes were incubated at 60 F and $50 \mathrm{~F}$. Maximum sporulation occurred in both media after nine days at $60 \mathrm{~F}$ and 18 - 20 days at $50 \mathrm{~F}$.

Table 1-1 shows the results of sporulation at $60 \mathrm{~F}$ : With the four strains tested, the yield of refractile spores in the TPGY medium was approximately four-fold higher than in TPG medium. As shown in Table 1-2 at $50 \mathrm{~F}$ the refractile spore yield in TPGY medium was two to three fold 
higher than in TPG medium for three of the strains and seven fold higher for Minneapolis strain.

Following these results small lots of spore suspension were prepared in $200 \mathrm{ml}$ of TPGY medium in square bottles incubated with screw caps tight. A suspension of the Beluga strain was produced at $50 \mathrm{~F}$ and suspensions of the Beluga and Minneapolis strains were produced at $46 \mathrm{~F}$. At $46 \mathrm{~F}$ the yields of per $\mathrm{ml}$ of TPGY medium were Beluga $30 \times 10^{6}$ and Minneapolis $19 \times 10^{6}$, whereas in TPY medium the yields were less than $5 \times 10^{6}$ per $\mathrm{ml}$. The comparative outgrowth characteristics of spores of the Beluga strain produced at $85 \mathrm{~F}, 50 . \mathrm{F}$ and $46 \mathrm{~F}$ have been determined in steamed ground haddock as reported under Phase V.

When preparing another suspenston of the Beluga strain at $50 \mathrm{~F}$ in screw cap bottles with tight caps one bottle burst due to pressure during incubation. Th1s indicated that it would be dangerous to continue this procedure. Screw cap bottles were then incubated with the caps loose, but this markedly reduced the yield with the Beluga strain to $16-20 \times 10^{6}$ refractile spores per $\mathrm{ml}$, although vegetative growth was excellent. In one test a one liter flask with $200 \mathrm{ml}$ of medium layered with vaspar was incubated at $50 \mathrm{~F}$ together with screw cap bottles with caps loose. With the Beluga strain the yield in bottles was $16-20 \times 10^{6}$ refractile spores per $\mathrm{ml}$ while the yield in the flask was $40 \times 10^{6}$ refract1le spores per $\mathrm{ml}$. A new spore suspension of the Beluga strain has been prepared at $50 \mathrm{~F}$ in flasks containing $400 \mathrm{~m} 1$ 
of TPGY medium layered with vaspar. The refractile spore yield per $\mathrm{ml}$ of medium was of the order $35-40 \times 10^{6}$ in different flasks.

Since it appears hazardous to conduct any further incubation of screw cap bottles with caps tight at present, the best procedure for producing spores at low temperatures appears to be TPGY medium in flasks layered with vaspar. 
Phase V

THE OUTGROWTH OF TYPE E SPORE INOCULA

IN SELECTED MARINE SUBSTRATES

Introduction: Fresh frozen haddock and cod fish fillets were used to prepare substrates to determine the outgrowth times of spores of Cl. botulinum Type $\mathrm{E}$ with regard to low temperature incubation and low dose irradiation. Haddock and cod fillets were selected, frozen, and shipped air freight to our laboratory from the Bureau of Commercial Fisheries Technological Laboratory at Gloucester. It is only through the excellent cooperation of Dr. Joseph Slavin and Mr. Louls Ronsivalli of the BCF laboratory that we have been able to conduct outgrowth experiments in. fresh fish substrates having a known history. We gratefully acknowledge their fine cooperation.

Procedures: The frozen haddock or cod fillets were partially thawed and finely ground with an electrically operated food grinder as previously described. The ground fish was dispensed in approximately 10-12 g amounts into $16 \times 125 \mathrm{~mm}$ screw-cap tubes by means of a Tremco heavy-duty caulking gun equipped with a stainless steel nozzle. The nozzle was made from an $8 \mathrm{in.} \mathrm{section} \mathrm{of} 3 / 8 \mathrm{in} .0 . D$. stainless steel tubing. It was welded to the barrel of the gun and served to deliver the ground undiluted substrate into the sample tubes. Alr pockets In $^{-}$the ground substrates were removed by centrifuging the f1lled tubes at 2,500 rpm for $5 \mathrm{~min}$. In a model ss-4 Serval Centrifuge. 
This centrifugation speed was sufficient to remove the air pockets without causing liquid-solid separation. In some experiments the tubed substrate was heated in flowing steam for $30 \mathrm{~min}$. to destroy the non-sporeforming microflora capable of growth at incubation temperatures below $50 \mathrm{~F}$. The tubed substrates were held at $34 \mathrm{~F}$ until inoculated. In other experfments the haddock fillets were handled to reduce additional contamination during preparation and not steamed. In this case, the substrate was held overnight at $34 \mathrm{~F}$ and inoculated the following day.

Samples were assayed for Type E toxin with trypsin digestion. The samples showing no toxin were also tested without digestion and by a new procedure using an acetate buffer system. The acetate method and a comparison of the results of three toxin assay procedures used are presented in Phase VII.

Results and Discussion: Various workers have used either mildly preheated or unheated spore inocula to determine the low temperature outgrowth characteristics of Type $E$ in marine product substrates. Whether unheated and preheated inocula at a comparable inoculum level show equivalent outgrowth times has not been firmly substantiated. In addition, the comparative outgrowth times of unheated and preheated inocula with respect to low-dose irradiation is unknown. The answers to these questions have practical significance, since inoculated pack studies using low spore inocula will be conducted on unheated 
spores, whereas tests with $10^{6}$ spores/gm will be conducted on preheated spores to prevent possible toxin carry over.

Table 5-1 shows a comparison of the outgrowth times of unheated and mildly preheated Inocula of the Beluga, 8E, Alaska, and Minneapolis strains with respect to low-dose irradiation and low temperature incubation. The experiment is based on an inoculum of $10^{6} \mathrm{viable}$ spores per tube and five replicates per variable. The data are tabulated in terms of the average and the range of outgrowth time. Where fewer than five tubes showed outgrowth, the outgrowth time for each tube is given. Without irradiation, unheated inocula showed almost the same outgrowth times with incubation at $42 \mathrm{~F}$ or at $40 \mathrm{~F}$ as spores preheated at $140 \mathrm{~F}$ for $13 \mathrm{~min}$. Similarly, unheated and preheated inocula showed practically the same outgrowth times when Irradiated with 0.1 or 0.2 Mrad.

The time of earliest toxin production in ground unsteamed haddock and cod with anaerobic incubation was studied. Triplicate samples were inoculated per variable with spores of the Beluga strain, vaspar sealed, and incubated at 46,42 , and $40 \mathrm{~F}$. The Beluga strain was selected, because spores of this strain often have shown faster outgrowth times than spores of three other strains tested. The inoculum levels choosen were $10^{6}$ and $10^{4}$ spores/gm of fish. 
At each sampling period, the vaspar was removed and the ground fish was transferred from each tube into a sterile $20 \times 150 \mathrm{~mm}$ screw-cap tube with three $5 \mathrm{ml}$ sterile water blanks added in three separate steps. As each water blank was added, the sample was shaken vigorously to remove the fish as completely as possible. It was tiecessary to dilute the substrates $1: 2$ to permit a toxin assay. At the time of sampling, $\mathrm{pH}$ determinations and aerobic plate counts were made. The plating medium used consisted of $1.5 \%$ Trypticase, $0.5 \%$ Phytone, $0.5 \%$ yeast extract, $0.5 \% \mathrm{Na} \mathrm{cl,} 0.2 \% \mathrm{glucose}$ and $1.5 \%$ agar. This medium was used and recommended by Dr. M. Ecklund of the Bureau of Commercial Fisherles Laboratory at Seattle.

The toxicity data on haddock and cod are shown in Tables 5-2 to 5-10. Also shown are the $\mathrm{pH}$ results and total aerobic plate counts on haddock. A condensation of the toxicity data is tabulated in Tables 5-11 and 5-12. With an inoculum of $10^{6}$ spores per gm, 0.1 and 0.2 Mrad Irradiation gave only a slight delay in the toxin outbreak time over similar unirradiated samples. However, with an inoculum of $10^{4}$ spores per $\mathrm{gm}$, irradiated samples showed no toxin after rather long incubation periods. For example, at $40 \mathrm{~F}$ no toxin was detected in Irradiated haddock after 60 days of incubation or at $42 \mathrm{~F}$ after 70 days, the longest time intervals tested. In cod, toxin was absent after 47 days at $42 \mathrm{~F}$ and after 40 days at $40 \mathrm{~F}$ in both unirradiated and irradiated product. With Incubation at $46 \mathrm{~F}$, both haddock and cod irradiated with 0.1 and 
0.2 Mrad showed a considerable extension of the toxin outbreak time over comparable unirradiated samples.

The bacterial flora that survived 0.1 and 0.2 Mrad irradiation and that grew anaerobically at 46,42 , and $40 \mathrm{~F}$ was examined. Our results confirm similar studies at the Bureau of Commercial Fisheries Laboratory at Seattle. All the cultures isolated were Gram positive rod and coccoid shaped bacterfa. Out of approximately 100 isolates, about $70 \%$ were catalase positive

The low temperature outgrowth potential. for spores of the Beluga strain produced at $50 \mathrm{~F}$ and $46, \mathrm{~F}$, was compared to that for spores produced at $85 \mathrm{~F}$. The low temperature spore crops were produced in TPG medium plus $1.0 \%$ yeast extract, as already described. As shown in Table 5-13, the low temperature spores tended to give somewhat shorter outgrowth times in steamed ground haddock with incubation at 40 and $38 \mathrm{~F}$ irrespective of 0.1 or 0.2 Mrad irradiation. In general, the difference in outgrowth times between spores produced at $46 \mathrm{~F}$ and those at $50 \mathrm{~F}$ was smal1. This is fortunate, since in the production of spore crops, the yield of spores was considerably higher at $50 \mathrm{~F}$ than at $46 \mathrm{~F}$.

While the outgrowth data does not appear to seriously invalidate experiments with spores produced at $85 \mathrm{~F}$, the results indicate the desirability of using spores produced at $50 \mathrm{~F}$ in future experiments. This appears particularly true at incubation temperatures of $42 \mathrm{~F}$ and below. 


\section{TOXIN ASSAY PROCEDURES}

Introduction: As discussed before, an attempt has been made to improve the sensitivity of the assay procedure for $\mathrm{Cl}$. botulinum Type E toxin. This phase describes a new technique using a sodium acetate buffer system. In addition, it describes work on the cause of nonspecific mouse deaths. The procedures used w11l be presented in the results and discussion section.

Results and Discussion: The toxin assay results shown in Tables 7-1 and 7-2 were tabulated from the toxicity data presented in Phase V. The experimental procedures used in these experiments have been described. It should be emphasized that the results are based upon undiluted and unsteamed ground haddock and cod substrates and upon anaerobic incubation.

At each sampling period, the haddock and cod samples were assayed for Type E toxin after trypsin digestion using the conventional phosphate buffer method. All samples showing no toxin were reassayed without trypsin digestion, since there was the possibility that proteolytic enzymes from the normal microflora had already activated the toxin, if toxin was present, and that further activation with trypsin would only cause degradation of the toxin. All samples showing notoxin by the phosphate buffer-trypsin digestion procedure also were assayed for toxin using a new procedure. It involved the use of a sodium acetate 
buffer combined with trypsin digestion. As shown in Table 7-1, several additional samples, which were negative for toxin by the phosphate-buffertrypsin digestion procedure, contained Type E toxin when assayed undigested and by the acetate method.

The acetate procedure consisted of plpetting about $2 \mathrm{gm}$ of a blended fish sample into $2 \mathrm{ml}$ of filter-sterilized $0.5 \mathrm{M}$ sodium acetate buffer at $\mathrm{pH} 5.5$. The buffered samples were held at $38 \mathrm{~F}$ for 20-24 hours to cause extraction of intracellular bound toxin and to release possible adsorbed toxin. Then $0.2 \mathrm{ml}$ of a freshly prepared $10.0 \%$ trypsin solution was added to each sample. After addition of trypsin, the samples were incubated at $98 \mathrm{~F}$ for 3 hours. Dupllcatemice, protected and unprotected with Type $E$ antitoxin, each were infected intraperitonally with $0.5 \mathrm{ml}$ of the trypsin digest.

There are several reasons for selecting the sodfum acetate buffer system and for trypsin digesting food samples at a lower pH and longer time than commonly are used in the phosphate-buffer-trypsin procedure. Detection of low levels of Type $E$ toxin in food substrates is complicated by the fact that the toxin appears to by bound intracellularly and is released principally through cell lysis. Our work has shown that Type E vegetative cells do not lyse as readily when grown at low temperatures as they do at higher temperatures. Therefore, an apprectable amount of toxin may pass undetected unless some procedure is used to extract 
It or to cause the vegetative cells to lyse. Ultrasonics"was investigated in an attempt to disrupt vegetative cells in order to release the bound toxin. However, sonification of a blended fish homogenate contalning a known level of toxin caused a reduction in the toxicity of the sample. Adsorption of toxin on the finely dispersed fish particles was belleved to be responsible for this loss in toxicity. This possibility was discussed in our annual report dated June 29, 1963 - June 28, 1964.

A suitable means of extracting bound toxin from vegetative cells was sought. Little information is available in this area. Sakaguchi and Sakaguchi (1959) employed a sodium acetate buffer to extract toxin from cells. Our preliminary tests indicated that $0.5 \mathrm{M}$ sodium acetate buffer at $\mathrm{pH} 5.5$ had no detremential effects on white mice when injected intrapetioneally. Neither did it have any adverse affect on Type $E$ toxin when used in conjunction with trypsin digestion.

In the conventional phosphate-buffer toxin assay procedure, the sample is trypsin digested at $\mathrm{pH}$ 6.0-6.2. Duff et. al. (1956) observed that activation of Type $\mathrm{E}$ toxin was faster at $\mathrm{pH} 6.0$ than at $\mathrm{pH} 5.2$; but they stated that the same toxicity was reached at $\mathrm{pH} 5.2$, although at a considerably slower reaction rate when the concentration of trypsin was increased. Dolman (1964) has reported very high Type E toxin titers with trypsin activation at $\mathrm{pH} 5.8$ and $3-4$ hours of incubation at $98 \mathrm{~F}$. The above work suggested the desirability of testing a sodium acetate buffer system and trypsin digestion at a lower $\mathrm{pH}$ and for a longer 
digestion time. Also, our own results had indicated that Type E toxin was much more heat stable at $\mathrm{pH} 5.0-5.25$ than at $\mathrm{pH} 6.0$, thereby reducing possibly toxin destruction during prolonged trypsin digestion at $98 \mathrm{~F}$.

A comparison of the three toxin assay procedures conducted on identical samples is shown in Table 7-2. The samples tested were inoculated ground haddock and cod substrates that had been incubated at $40 \mathrm{~F}$. Out of 78 samples assayed, 10 showed toxin by the phosphate buffertrypsin digestion procedure, 24 exhibited toxin undigested, and 30 showed toxin by the acetate method using trypsin digestion. The results indicate no advantage in testing for toxin by the conventional phosphate buffer procedure, but suggest that all samples should be toxin assayed undigested and by the new acetate method. The role of sodium acetate in the detection of low levels of toxin is not clear. It may cause extraction of toxin from intact cells, cause a release of adsorbed toxin, or simply establish a more favorable pH for toxin activation.

The $\mathrm{pH}$ of the acetate buffer used will depend upon the pH of the sample tested. For example, ground fish substrates incubated anaerobically showed a gradual reduction in $\mathrm{pH}$ from about 6.6 to 6.0 (Phase V). However, fresh fish substrates incubated aerobically (Phase XVII) showed a marked increase to as high as $\mathrm{pH} 7.5$ to 8.3 . To maintain a sample at $\mathrm{pH} 5.2$ - 5.5 for trypsin digestion, a $\mathrm{pH} 5.5$ buffer was used for the samples incubated anaerobically, whereas a pH 5.0 buffer was 
used for the samples incubated aerobically. Samples assayed without trypsin digestion also were diluted $1: 2$ in the same buffer that was used with the trypsinized samples. Untrypsinized samples were held 20-24 hours at $38 \mathrm{~F}$ before being injected into white mice as were samples for trypsin digestion.

Verification of toxin in a sample involves the intrapertioneal injection of white mice both unprotected and protected with specific antitoxin. Death of the unprotected mice and survival of the protected mice constitutes a positive test for the specific toxin. In our experience, samples containing Type E toxin invariably cause death of the unprotected mice within 24 hours. However, mice protected with antitoxin are observed up to 4 days before they are destroyed and test completed.

Ground unsteamed haddock and cod substrates, blended and injected Into mice, often have shown a nonspecific toxicity. That is, protected mice died in addition to the unprotected mice. Occassionally, such false botulinal deaths occurred within 24 hours after injection, but deaths between 24 and 48 hours were more common. In some cases death occurred between 48-72 hours after infection. Often the mice protected with Type $E$ antitoxin died faster than unprotected mice Injected with the same sample.

In some cases, the nonspecific toxicities could be eliminated by $1: 10$ 
dilution of the sample. Obviously, such a procedure diluted any toxin present and reduced the sensitivity of the assay procedure. Also, freezing eliminated nonspecific mouse deaths in some blended haddock samples. Since freezing was shown to have no effect on the destruction of Type E toxin, this method was used with partial success to circumvent the problem.

Nonspecific toxicities have been encountered only with unirradiated and 0.1 Mrad irradiated ground haddock and cod samples. Samples Irradiated with 0.2 Mrad have never shown nonspeciflc mouse deaths. In general, the frequency of these deaths has been greather with fresh haddock and cod Incubated aerobically than with similar product incubated anaerobically. However, this frequency may merely reflect the fact that the substrates used for anaerobic incubation were prepared from product that had been frozen, whereas substrates incubated aerobically in more recent experiments have been prepared from fresh unfrozen fillets.

The earliest appearance of nonspecific toxicities in fresh haddock incubated aerobically at low temperatures is shown in Table 7-3. Decreasing temperatures form 50 to $40 \mathrm{~F}$ and irradiation with 0.1 Mrad in comparison to unirradiated product caused a delay in the onset of symptoms and the eventual occurrence of nonspectfic mouse deaths.

The 1iterature on the occurrence of nonspecific toxicities in mice 
Indicates that many workers have encountered this problem in assays for cl. botulinum toxins. Most investigators have simply ascribed such false toxin results to the presence of some toxic by-product of bacterial growth. Notable among such compounds are ammonia and certain amines produced during the microbial decomposition of proteins (Dack, 1965).

In a study of the Incidence of $\mathrm{Cl}$, botulinum Type $\mathrm{E}$ in the Great Lakes region, Bott et. al. (1966) encountered nonspecific toxicities in mice inoculated with cultures of the intestinal contents of fish. They attributed these nonspecific deaths to a slow acting bacterial toxin or to an infection. No attempt was made to fsolate any infectious organism in this work.

In our experience, mice Injected with haddock and cod samples giving nonspecific toxicities have shown a rough coat, a slight diarrhea and usually an apparent infection of the eyes. Symptoms suggested that some infectious organism might be involved. An attempt was made to show whether septicemia existed. Duplicate mice were injected Intraperitoneally with a sample known to possess a nonspecific toxicity. Just before death, one mouse was anesthetized with chloroform in preparation for a cardiac puncture. The hafr between the front legs of the animal was clipped away and the area disinfected with $70 \%$ enthanol. A disposable sterile plastic syringe equipped with a 26 gauge needle was used to withdraw a blood sample. The blood was inoculated into PE-2 
medium (Folinazzo and Troy, 1954) and Incubated at 98 F. Also, a wet mount preparation of the blood was examined using dark phase contrast microscopy.

Microscopically, the blood smear showed a massive bacterial infection which also was verified in the $\mathrm{PE}-2$ subculture. Several additional mice inoculated with samples giving nonspecific deaths were bled before death according to the procedure described above. All the subcultures showed growth after 24-48 hours of incubation at $98 \mathrm{~F}$. Since cardiac punctures of seven uninoculated healthy mice taken at different time periods showed no growth when subcultured in a similar manner, the aseptic technique used to obtain the blood cultures appeared satisfactory. Blood samples were taken from mice showing nonspecific symptoms shortly before the anticipated time of death and also in some cases from mice at the earliest appearance of 11lness.

A smear of each blood culture was made after incubation, heat fixed, and Gram stained. To Isolate Gram negative bacteria, the subcultures were streaked on Difco EMB or Mac Conkey agar medium. Cultures of Gram positive organisms were purified by streaking on Tryptone-Peptoneyeast extract agar (TPY) if Gram negative bacteria were absent or on Bacto-Phenylethanol agar, a selective medium, if the culture showed a mixed flora. Well isolated colonies on the streak plates were Inoculated into PE-2 medium. To insure the purity of the 1solates, each culture was restreaked on TYP medium and after 24-48 hours of 
Incubation an isolated colony was again picked into "PE-2 broth medium. After Incubation, the PE-2 cultures were examined microscopically for purfty and stored under refrigeration.

Preliminary results indicated that growth of a few isolates was markedly improved by the addition of sterile Bacto-Horse Serum to the subculture medium. As a routine procedure, therefore, blood samples were cultured in PE-2 medium containing about $2.0 \%$ horse serum. Also, this same concentration of horse serum was added aseptically just before pouring TPY medium for streak plates. Generally, the same bacteria favored by the addition of the horse serum showed enhanced growth when streaked and incubated in a candle jar.

The cultures obtained from mice showing nonspecific toxicity symptoms were identified as to genus and where possible, to species. Gram negative rod-shaped bacteria were separated by the scheme of Shewan et. al. (1960) and that of Cowan and Steel (1965). Members of the Family Enterobacteriaceae were classified by the biochemical tests compiled by Johnson et. al. (1966). Gram positive bacteria were divided Into appropriate genera by the systematic key of Cowan and Steel (1965). The biochemical tests were conducted according to the procedures recommended by Collins (1964), with the exception that motility was determined in the medium developed by Ball and Sellers (1966).

Currently, 23 isolates associated with nonspecific toxicities in mice 
Inoculated with haddock samples undergoing spoilage have been identified. The history of each sample with regard to incubation time and temperature and whether the sample was irradiated is shown in Table 7-4. No pattern is apparent concerning any of these factors relative to the organism isolated.

Generically, 12 isolates were Identified Proteus, one Alcaligenes, 2 Aerobacter, one Actinobacillus, 3 Enterococci, and 4 Erysipelothrix. Since Proteus, Alcaligenes, Aerobacter and Enterococcl are normally inhabitants of mammalian intestinal tracts, it is difficult to speculate on the orgin of these cultures. While they may represent secondary invaders, their presence in partially spoiled fish is conceivable. The cultures identified as Actinobacillus, and Erysipelothrix Insidosa are believed to have originated from the partlally spoiled haddock samples that were injected into mice, since they are not recognized as normal Inhabitants of the mouse intestinal tract.

The Enterococcus cultures conformed to the cultural characteristics presented in Bergey's Manual for this group with the exception that the organisms isolated failed to grow at $113 \mathrm{~F}(45 \mathrm{C})$ in Brain Heart Infusion broth. Little is known about the limiting growth temperatures of Enterococci from marine environments. It is possible that Enterococci of marine orign may behave somewhat differently from strains of mammalian intestinal sources with regard to their maximal growth temperature. 
To determine the possible infectivity of each isolate for mice, 48 hour PE-2 cultures were injected intrapertioneally. Two mice each were injected with $0.5 \mathrm{ml}$ of a culture and a $1: 10$ dilution of the same culture. The mice were observed for nonspecific symptoms up to 4 days if death did not occur earlier.

Most of the strains Identified as Proteus caused deaths 24-48 hours after injection of the undiluted culture. However, none of the Proteus cultures produced death when 1:10 dilutions were injected. The cultures Identified Alcaligenes and Aerobacter gave results similar to Proteus, producing deaths when undiluted cultures were injected, but none when diluted. The Actinobacillus and Enterococci cultures falled to produce death of mice when injected efther undiluted or diluted. However, the Erysipelothrix cultures produced deaths both undiluted and diluted 1:10.

The PE-2 cultures which failed to produce mouse deaths do not necessarily mean that the organisms may not be infectious under certain conditions. Injection of partially putrefied fish protein intrapertioneally into mice may lower their resistance so that organisms normally considered as nonpathogenic may invade the blood stream and eventually cause death. Mice injected with spolled fish samples often show signs of illness within a few minutes, although the mice usually recover if the sample does not contain a nonspecific toxicity factor, or seemingly from the results reported here, an infectious organism. 
The symptoms observed with mice injected with the Erysipeothrix cultures resemble those seen in mice injected with haddock samples giving nonspecific toxicities. Blood cultures drawn from symptomatic mice several hours after injection indicated that the organism had invaded the circulatory system. These results suggest that E. Insidosa may be the principal bacterium producing massive infections of mice Injected with fish samples undergoing decomposition.

The cultural characteristics of the $\underline{E}$. insidosa 1solates are shown in Table 7-5. The four cultures each gave identical reactions. The morphological and physlological behavior of the cultures are identical to those described in Bergey's Manual (1957) with the exception that all of the isolates showed the ability to grow at low temperatures. Smith, Conant, and Overman (1964) cite limiting growth temperatures of $59 \mathrm{~F}(15 \mathrm{C})$ and $111 \mathrm{~F}(44 \mathrm{C})$ for E. Insidosa. The cultures isolated falled to grow at $113 \mathrm{~F}(45 \mathrm{~F})$, but grew at $50 \mathrm{~F}(10 \mathrm{C})$ when inoculated Into sterile blended haddock. Additional work suggests growth of the four cultures at an even lower temperature.

E. Insidosa belongs to the Famfly Corynebactertaceae and is the only recognized species in Bergy's Manual. The organism is reported to be widely distributed in nature and is known to cause human erysipeloid and a mouse septicemia. The organism occurs in the surface slime of both fresh and salt water fish. Halstead (1962) indicates that fish handlers often are infected by handling the remains of fish exhibiting 
putrefactive decomposition.

Work on cod has substantiated the cause of the false botulinal reactions In mice as being due to an infection rather than some slow acting toxic by-product of bacterial growth. Uninoculated and unirradiated fresh cod incubated at $50 \mathrm{~F}$ for 3 weeks was extremely toxic, producing mouse deaths within 24 hours. The mice were definitely 111 about 2 hours after injection. Blood cultures taken at the first sign of illness showed a mixed Infection of streptococcl and of Gram negative rods. The cultures as yet have not been identified. Injection of the supernatants of the cod samples produced mouse deaths within 48 hours, whereas the same samples heated in flowing steam for $15 \mathrm{~min}$ or filtered through a sterile Morton bacterlological filter gave no deaths up to 4 days.

Several attempts were made to eliminate an infection in mice injected with blended haddock samples showing partial or definite spoilage. Reference to the effect of freezing and dilution of the fish has been cited. Centrifugation also removed some nonspecific reactions from certain samples. The principal objection to centrifugation followed by injection of the supernatants is the possibility that a significant quanty of toxin may be lost because botulinal toxins appear to be bound intracellularly.

The possibility of elimination of an infection with a chemical treatment 
was investigated. Blended haddock samples known to cause nonbotulinal deaths of mice were diluted 1:2 in sodium acetate buffer containing 1.0\% phenol. The samples were held overnight at $38 \mathrm{~F}$ and injected into mice. The intrapertioneal injection of phenol into mice produced a rapid and severe tremor, but the mice seemed to recover within a few minutes. The phenol treatment had no effect on the detection of Type $E$ toxin added at low levels to blended haddock possessing a nonspecific toxicity. While phenol eliminated some infectious organisms, the results were often inconsistent.

The possibility of using a mild heat treatment sufficient to destroy any Infectious bacteria but moderate enough not to affect a loss of Type E toxin was studied. Unfortunately, this attempt was unsuccessful. The next step was to investigate the posstble use of antiblotics to control infections.

Each of the blood culture isolates associated with nonspecific mouse deaths was screened against several antiblotics. Pour plates of the isolates were prepared using TPY agar. After solidification of the medium, Mutidisks (Colab Laboratories, Chicago Heights, Illinois) containing a combination of Novobiocin, Chloramphenicol, Erythromycin, Lincomycin, Neomycin, Penicillin, Dihydrostreptomycin, and Tetracycline were placed on the medium and the plates incubated at $98 \mathrm{~F}$. The plates were examined for zones of growth inhibition after 48 hours of incubation. 
All of the isolates were sensitive to either Chloramphenicol or Tetracycline and most were Inhibited by both antibiotics. The E. Insidosa cultures were sensitive to Pencillin as well as Chloramphenicol and Tetracycline. According to the antiblotic sensitivity: tests, Chloromyetin (Chloramphenicol) and Terramycin (Oxytetracycline) were choosen for further study. Assuming that about 20 gram mice would be used for toxin assays, the antibioitc levels were calculated on a weight basis according to the manufacture's recommended dose for humans. Approximately 18 hours before samples with nonspecific toxicities were assayed for toxin, mice were injected intrapertioneally with the antibiotics. The two antibiotics were mixed and injected simultaneously. Each mouse received $0.4 \mathrm{ml}$ equivelent to $2.0 \mathrm{mg}$ of Chloromycetin and $0.25 \mathrm{mg}$ of Terramycin. Just before injecting the test sample into the antibiotic-protected mice the next day, each mouse was given a second injection of the antiblotics. The results of the antibiotics with blended haddock samples showing nonspecific toxicities have been encouraging. Mice have not shown nonspectfic symptoms or illness up to 48 hours and in most caseshave lived for 4 days after injection. 


\section{Phase XIII}

\section{RADIATION RESISTANCE OF SPORES OF TYPE E IN PHOSPHATE}

BUFFER AND MARINE HOMOGENATES IN RELATION TO INCUBATION TEMPERATURE

Introduction: The resistance of spores of four $\mathrm{Cl}$. botulinum Type $\mathrm{E}$ strains to $\mathrm{Co}^{60}$ Irradiation in blended haddock and phosphate buffer was summarized in our last annual report. This section presents some additional data on the irradiation resistance of spores of the Beluga strain in Trypticase - Peptone glucose (TPG) medium.

Procedures: The procedures used were the same as those discussed earlier, with two exceptions. First, samples were irradiated with a $\mathrm{Co}^{60}$ source located at the Illinols Institute of Technology rather than at the Admiral Corporation. The Admiral facility was dismantled in January 1965. The second exception concerns the medium used to recover the irradiation survivors. The medium formerly used consisted of $5.0 \%$ Bacto - Peptone and $16.0 \%$ Bacto - gelatin. The use of gelatin necessitated incubation at $68 \mathrm{~F}$ to prevent diffusion of colonies throughout the medium. Bacto-agar at a concentration of $1.5 \%$ was substituted for the gelatin previously used. This permitted incubation of the recovery medium at $85 \mathrm{~F}$. It was shown that colony counts at $85 \mathrm{~F}$ were equivalent to those obtained at $68 \mathrm{~F}$.

Results and Discussion: The radiation resistance of spores of the Beluga strain in TPG medium closely approximates that in blended haddock homogenate, as shown in Table 13-1. D-values are shown for 
$10^{6}$ inactivation and the exponential portions of survivor curves. The results indicate that TPG medium may be a suitable substrate to simulate marine or other food products for the preliminary determination of the irradiation resistance of spores of other Type E strains. 
Phase XVI

RADIATION RESISTANCE OF SPORES

PRODUCED FROM RADIATION SURVIVORS

Introduction: It has been shown that certain bacteria, when subjected to repeated irradiation, may produce mutant organisms which exhibit varied morphological and physiological characteristics from the parent culture (Erdman et. al., 1961; Idziak and Thatcher, 1964; and Pontefract and Thatcher, 1965). Also, repeated irradiation of survivors can give rise to aberrant strains of bacteria which are more resistant to irradiation than the parent population. Erdman et. al. (1961) reported that vegetative cells of a $\underline{C 1}$. botulinum Type A strain recycled ten times at 0.2 Mrad were considerably more resistant to $\mathrm{Co}^{60}$ radiation than cells of the parent suspension. When vegetative cells of the irradiated strain were permitted to sporulate, the spores exhibited a constant and increasing percent survival at each radiation dose over spores of the parent. Thus, it was shown that the increased resistance to radiation could be transmitted from the vegetative cell to the spore. In addition, this increased resistance could be transmitted from these spores to the next generation of vegetative cells.

In contrast to the results with Type A cells, Erdman et. al. (1961) showed that vegetative cells of two Type E strains, when subjected to repeated 0.2 Mrad irradiation displayed no perceptible increase in their resistance 
to radiation. Apparently, vegetative cells of the different serological types of $\mathrm{Cl}$. botulinum vary in their response to repeated doses of ionizing radiation .

The purpose of this study was to investigate the effect of repeated $0.8 \mathrm{Mr}$ irradiation on spores of $\underline{\mathrm{Cl}}$. botulinum Type $\mathrm{E}$, particularly with respect to changes in its resistance to $\mathrm{Co}^{60}$ irradiation and its low temperature outgrowth ability.

Procedures: Sterilized TPG medium $(20 \mathrm{~m} 1)$ was pipetted into $20 \times 150 \mathrm{~mm}$ screw-cap tubes. The medium was chilled and inoculated with $0.5 \mathrm{ml}$ spore suspension of the Beluga strain, equivalent to $2 \times 10^{5}$ spores $/ \mathrm{ml}$ of medium. For each experimental variable, triplicate tubes of medium were inoculated and irradiated. Samples were irradiated with $0.1,0.2$, $0.4,0.6$, and $0.8 \mathrm{Mrad}$ doses in a Cobalt-60 source located at the Illinois Institute of Technology. To prevent possible spore germination, the samples were irradiated at a temperature of $35 \mathrm{~F}$. A1so, the samples were packed in ice in an insulated chest for transit to and from the radiation facility. As soon as possible after irradiation, the samples were returned to our laboratory. Each experiment included an inoculated unirradiated sample which was handled in the same manner as the irradiated samples .

For each irradiation dose, two of the three replicate tubes were mixed with a Vortex agitator and poured aseptically into sterile $25 \times 200 \mathrm{~mm}$ screw 
cap tubes. This size tube was used to give sufficient head space for gas production during incubation. Heat sterilized sodium thioglycollate (20\%) was added to the medium to give a final concentration of $0.1 \%$. After overlaying the medium with melted vaspar and tempering to $85 \mathrm{~F}$ in a water bath, the samples were incubated at this temperature.

The number of irradiation survivors for the five radiation doses used was determined as quickly as possible after irradiation. Also, the number of viable spores in a corresponding unirradiated control tube of TPG medium was determined. A five tube replicate deep-tube recovery technique was employed. Serial tenfold dilutions were prepared and appropriate amounts pipetted into $16 \times 125 \mathrm{~mm}$ screw cap tubes to give about 10-30 colonies per tube. The recovery medium consisted of $5.0 \%$ Bacto - Peptone and $1.5 \%$ Bacto Nobile agar. Sterilized sodium thioglycollate was added to the melted medium to a concentration of $0.1 \%$ just before use. Each inoculated tube was poured with about $13 \mathrm{ml}$ of the medium. As each set of ten tubes was poured, they were placed in a cold water bath to chill and solidify the medium. The tubes were incubated at $85 \mathrm{~F}$, then colony counts made after 48 hours, one week, and one month of incubation.

After 28-30 hours of incubation, one of the vaspar sealed cultures for each irradiation level was chilled in an ice water bath in preparation to harvest the six respective spore suspensions. The vaspar was removed 
from each tube with sterile cotton tipped applicator sticks and the sporulated cultures were pipetted into Nalgene screw-cap centifuge tubes. After centrifuging at 9,500 $\mathrm{rpm}$ for $20 \mathrm{~min}$ in a Servall model SS-4 anglehead centrifuge, the supernatants were poured off. Each spore sediment was resuspended in $20 \mathrm{ml}$ of sterile prechilled distilled water. The suspensions were pipetted into $20 \times 150 \mathrm{~mm}$ screw-cap tubes and stored at $34 \mathrm{~F}$. Petroff-Hausser refractile spore counts were made and the percentage of germinated spores was estimated by a methylene blue staining procedure.

The second set of vaspar sealed cultures was incubated for 5 days at $85 \mathrm{~F}$. At the end of incubation, the toxicity of the cultures in terms MLD's of Type E toxin was ascertained with and without trypsin digestion. Also, the $\mathrm{pH}$ of each culture was determined.

For each successive irradiation cycle, the series of steps described above was repeated using as in inoculum the spores produced from the 0.8 Mrad survivors obtained from the preceding experiment.

Results and Discussion: Thr effect of the length of incubation at $85 \mathrm{~F}$ on the yield of refractile spores obtained at each irradiation dose used is shown in Tabie 16-1. After 24 hours of incubation the cultures exhibited good vegetative cell growth, but practically no sporulation. Soon after 24 hours, sp rulation apparently became rapid, because 30 hour cultures 
showed about $70-80 \%$ spores. Incubation for 48 hours gave a lower refractile spore yield and a higher percentage of germinated spores than cultures incubated for 30 hours. To recover the highest yield of refractile spores, all subsequent cultures were centrifuged after 30 hours of incubation.

During the second irradiation experiment it was apparent that it would be more convenient to refrigerate the sporulated cultures overnight after 30 hours of incubation and harvent each spore crop the next day. Unfortunately, spores held overnight at $34 \mathrm{~F}$ in the sporulation medium germinated extensively, as indicated in Table 16-2. It was evident from this experiment that to minimize spore germination, the spores would have to be harvested immediately from the sporulation medium at the end of incubation. In contrast to the rapid germination of spores in the culture medium at low temperatures, spores held in aqueous suspension showed no detectable change in refractility even after being stored for several months. The fact the number of refractile spores decreased with increasing irradiation doses can be attributed to an indirect effect of radiation on the sporulation medium rather than a direct effect upon the spores themselves. Spores of the parent Beluga suspension were inoculated into TPG medium and irradiated with $0.8 \mathrm{Mrad}$. The irradiated sample was centrifuged and the spores were resuspended in fresh unirradiated TPG medium and incubated at $85 \mathrm{~F}$. The culture produced a suspension with a refractile count equal to $44 \times 106$ spores/ml as shown in Table 16-3. The count was not much less than that obtained from a corresponding unirradiated inoculated sample. However, 
when uninoculated TPG medium was irradiated with the same dose and then inoculated with unirradiated spores, a suspension having a much lower refractile count was produced. In fact, the yield of spores in latter case was almost as low as that obtained by simultaneously irradiating the medium and spores with $0.8 \mathrm{Mrad}$.

The yield and viability of spores of the four recycled suspensions produced from 0.8 Mrad survivors are shown in Table 16-4. Each suspension showed about the same refractile spore count. Also, the first, second, and third generation suspensions designated $s_{1}, s_{2}$ and $s_{3}$ exhibited about the same percent spore viability. However, spores of the fourth generation suspension designated $\mathrm{S}_{4}$ showed a somewhat higher viability than spores of the preceding suspensions. This increased viability suggested that the S4 spores might show shorter outgrowth times than spores of the parent suspension if inoculated into a fish substrate and incubated at low temperatures.

However, when tested in undiluted, steamed haddock, spores of the $\mathrm{S}_{4}$ suspension displayed longer outgrowth times when incubated at 42 and $40 \mathrm{~F}$ than the outgrowth times of spores of the parent suspension (Table 16-5). It is apparent that a large fraction of the $S_{4}$ population, which showed outgrowth in Peptone-Agar at $85 \mathrm{~F}$, were not capable of rapid outgrowth at low temperatures as suspected.

The percent survivors of spores of the parent suspension and of the three suspensions produced from 0.8 Mrad survivors for each radiation dose 
employed are shown in Table 16-6. The irradiation resistance values were obtained from plots of the survivor data and are presented in Table 16-7. The resistance figures for spores of the four suspensions are shown in terms of D-values and 1ag. D-values were determined from the exponential portion of each survivor curve and for $10^{6}$ inactivation by extrapolating each survivor curve through 6 log cycles of reduction, then dividing this dose by 6 . Calculation of D-values for 106 inactivation tends to compensate for the "shoulder" effect of survivor curves, whereas D-values taken from the exponential portion of such curves ignore the "shouldex". The lag value provides a convenient way of expressing the "shoulder" effect in quantative terms. It is defined as the irradiation dose for a survivor curve to traverse the first log cycle of reduction. Spores of the $S_{1}, S_{2}$, and $S_{3}$ suspensions showed approximately the same D-values. The most important difference between the survivor curves was the absence of a "shoulder" for spores of the $s_{3}$ suspension.

The disappearance of the characteristic "shoulder" for the $S_{3}$ suspension might be partially explained by the reduced count found with the unirradiated control sample. The inoculum used should have given a control count equal to $2 \times 10^{5}$ spores $/ \mathrm{m} 1$. However, a count of $7.4 \times 10^{4}$ spores $/ \mathrm{m} 1$ was obtained indicating about a $60 \%$ reduction in the expected count. It is not known whether this reduction in count represents a partial loss in spore viability or perhaps rapid germination of these spores when inoculated into TPG medium. The experiment was repeated again using 
spores of the $S_{3}$ suspension as an inoculum. As shown in Table 16-8, the results in the second test corresponded to those obtained in the preceding experiment. A methylene blue stained preparation of the $s_{3}$ aqueous suspension showed about the same percentage of germinated spores as in the suspension when it was originally harvested.

Viable counts of the $\mathrm{S}_{4}$ suspension inoculated into prechilled TPG medium and held at $34 . F$ were made initially and after 24 and 72 hours at this temperature. The results of this experiment are shown in Table 16-9. The inftial count of $16 \times 10^{4}$ with $85 \mathrm{~F}$ incubation was only slightly lower than the theoretical count expected. After 24 hours, the sample showed about a $50 \%$ reduction in count over that obtained immediately after inoculation. The 72 hour count was practically the same as that obtained at 24 hours. After 72 hours the sample was centrifuged and the spore sediment examined to determine the extent of spore germination. A larger fraction of the inoculum was germinated in comparison to that seen in the stock aqueous suspension. Because of the rapid germination of spores of the $\mathrm{S}_{4}$ suspension, further work on the effect repeated irradiation of Type E spores was abondoned.

TPG cultures of the third generation 0.8 Mrad survivors incubated for 5 days at $85 \mathrm{~F}$ showed the same Type $\mathrm{E}$ toxin levels (2,000 MLD unactivated, $100,000 \mathrm{MLD}$ trypsin activated) and $\mathrm{pH}$ as a culture produced from spores of the parent Beluga strain. Although judged by only a limited number of cycles, there is no indication of a change in the toxin producing 
ability of Type $\mathrm{E}$ C1. botulinum through repeated 0.8 Mrad irradiation of its spores. 
Phase XVII

\section{TOXIN DEVELOPMENT IN FRESH MARINE PRODUCTS}

Introduction: This phase might logically fall under Phase V. However, since it represents a new approach to the determinations of toxin outbreak time in relation to the storage life of marine products and a new technique, it is reported as a distinct phase of our program which was not suggested in the proposal of November, 1965. In previous reports from this laboratory, data have been presented upon the outgrowth characteristics of Type E spores at low temperature under anaerobic conditions of incubation in 1:2 steamed haddock homogenates, undiluted steamed ground haddock and in nonsterile undlluted ground haddock prepared from frozen fish recelved from the Gloucester BCF laboratory. There have been valid obfections that many of our experiments do not reproduce the actual situation as 1 t may exist in unirradiated or irradiated fresh fish fillets.

In order to meet these objections and to place our experiments upon a perhaps more realistic basis we have devised a procedure based on the use of a screw cap jar $(13 / 4 \times 13 / 4 \mathrm{In})$ of $70 \mathrm{ml}$ capacity. With 40-45 grams of fish per jar this simulates the aerobic or semi-aerobic pack as may occur under commercial conditions. As the result of several conferences between Messrs. Slavin, Ronsivalli, Schmidt and co-workers the conclusion was reached that the Type E problem in irradiated fish could be approached in the following way. First, the determination by the fisheries scientists 
of the "maximum storage $11 \mathrm{fe}$ " of unirradiated and irradiated marine products stored at various temperatures based upon unanimous rejection by an untrained panel based on odor. This value (in terms of days storage at a given temperature) for unirradiated and irradiated marine products is called $\mathrm{X}$. Second, the determination of toxin development in inoculated fresh fish fillets, unirradiated and irradiated, at times representing $1 / 2 \mathrm{x}, \mathrm{x}, 2 \mathrm{x}$, 3X. It may be more desirable at times to use other fractions and multiples of $X$; such as, $1 / 2 \mathrm{X}, 3 / 4 \mathrm{X}, \mathrm{X}, 11 / 2 \mathrm{X}$ and $2 \mathrm{X}$.

Procedures: Haddock fillets were prepared and shipped by the Gloucester BCF laboratory. Fillets were prepared on Monday then shipped iced by air freight and arrived Monday afternoon. The shipment was held on ice overnight and the experiment began on Tuesday morning. The fars ( $13 / 4 \times 13 / 4$ in) were sterilized by flowing steam to eliminate vegetative organisms, as was also the stainless steel press and die used to cut plugs from the fish fillets. The operations of cutting the fillets and filling jars was conducted with sterile rubber gloves to reduce extraneous contamination. The jars, of $70 \mathrm{ml}$ capacity, were filled by weight with 40-45 grams of portions of the fish fillets. The jars were then refrigerated at $33-36 \mathrm{~F}$. After the required number of jars were fllled, the control unirradiated jars were inoculated and Incubated at the desired temperatures. By Wednesday morning, jars were inoculated, transported iced to the IIT $\mathrm{Co}_{60}$ facility and Irradiated with $0.1 \mathrm{Mr}$. The Irradiated jars were held refrigerated overnight, then returned to the laboratory and stored at the 
desired incubation temperature. On Thursday the jars were Inoculated and irradiated with the $0.2 \mathrm{Mr}$ dose. Three jars were provided for each varfable, inoculum level, radiation dose, storage temperature and time. Total plate counts were conducted on Tuesday, Wednesday and Thursday, as well as after irradiation to evaluate the inftial populations

The tests were conducted with spores of the Beluga strain inoculated at levels of $10^{6}, 10^{4}$, or $10^{2}$ per gram. At the $10^{6}$ level the spores were heated $15 \mathrm{~min}$ at $140 \mathrm{~F}$ to eliminate possible toxin carryover and the inoculum was based on the heat shocked count. The $10^{4}$ and $10^{2}$ inoculum was used without heat shock.

After storage the jars, were evaluated as follows:

Each sample was observed for odor by a six member panel of the laboratory and either accepted or rejected. It was not possible to maintain a panel of six in all cases due to absences of one or more members from the laboratory. Each sample was blended with $80 \mathrm{ml}$ of sterile water to give a $1-3$ blend. A portion of the blend was transferred to steile $20 \times 150 \mathrm{ml}$ screw cap tubes and frozen until toxin assays could be conducted; $\mathrm{pH}$ was determined on a portion of the blend. Serfal dilutions were prepared from the blend and total plate count at $70 \mathrm{~F}$ (at least five days incubation) was determined. The medium of Ecklund was used for total plate counts (Trypticase $15 \mathrm{gm}$, Phytone $5 \mathrm{gm}$, Yeast Extract $5 \mathrm{gm}$, Na $\mathrm{Cl} 5 \mathrm{gm}$, glucose $1 \mathrm{gm}$, Agar $\left.15 \mathrm{gm}, \mathrm{H}_{2} \mathrm{O} 1000 \mathrm{ml}, \mathrm{pH} 7.0\right)$. Toxin assays 
were conducted both undigested and with trypsin digestion by the sodium acetate procedure, as described in Phase VII. Since it was found that the $\mathrm{pH}$ of the samples under these storage conditions increased above 7.0 to as high as 8.0 , the $\mathrm{pH}$ of the acetate buffer was reduced to 5.0 in order to have the acetate buffer-blend mixture at $\mathrm{pH} 5.5-5.6$. The untrypsinfzed samples were tested after holding overnight at $38 \mathrm{~F}$. Trypsinized samples were digested for three hours at $98 \mathrm{~F}$. Toxin assays were conducted by the intraperitoneal injection of $0.5 \mathrm{ml}$ into duplicate white mice. In some cases, simultaneous protection tests were run using Type $E$ antiserum; in others, the samples were run first without protection and toxin verified in a repeat test with antiserum protection.

Three experiments have been conducted on haddock:

1. Samples inoculated with $10^{2}$ and $10^{4}$ spores of the Beluga strain prepared at $85 \mathrm{~F}$. Storage at $50 \mathrm{~F}$ for $1 / 2 \mathrm{X}, \mathrm{X}$, $2 X$. Samples inoculated with $10^{4}$ and $10^{6}$ spores storage at $46 \mathrm{~F}$ for $1 / 2 \mathrm{X}, \mathrm{x}, 2 \mathrm{x}$.

2. Samples inoculated with $10^{4}$ and $10^{6}$ spores of the Beluga strain prepared at $85 \mathrm{~F}$. Storage at $42 \mathrm{~F}$ and $40 \mathrm{~F}$ for $1 / 2 \mathrm{x}, 3 / 4 \mathrm{x}, \mathrm{x}, 11 / 2 \mathrm{x}, 2 \mathrm{x}$.

3. Samples inoculated with $10^{4}$ and $10^{6}$ spores of the Beluga strain produced at $50 \mathrm{~F}$. Storage at $42 \mathrm{~F}$ and $40 \mathrm{~F}$ for $3 / 4 \mathrm{X}, \mathrm{x}, 11 / 2 \mathrm{x}, 2 \mathrm{x}$. 
Results: Table 17-1 shows the total plate counts prior to and following irradiation. On Tuesday, the day of arrival, the intitial counts ranged from $15 \times 10^{4}$ to $46 \times 10^{4}$ for the three experiments. During storage in fars at 33-36 F the counts rose moderately. Following irradiation at $0.1 \mathrm{Mr}$, counts were reduced to $11-21 \times 10^{2}$ while after $0.2 \mathrm{Mr}$ counts were reduced to $7-16 \times 10^{2}$. In these experiments $0.2 \mathrm{Mr}$ irradiation resulted in only $0.1 \%$ greater reduction of the infitial count than did $0.1 \mathrm{Mr}$ irradiation. Tables 17-2 to 17-13 show the data of all the tests in haddock. Triplicate jars were used for each variable. The tables are arranged to show Irradiation dose, incubation time in days, fraction or multiple of $X$, total count on one jar of three, $\mathrm{pH}$ range for three jars, rejection based on odor and toxin results. Since the panel varled from three to six members, rejection is expressed as a fraction. With six panel members and three jars a figure of $11 / 18$ would Indicate 11 rejections in the 18 judgements. A survey of the recorded acceptance - rejection judgements showed no one Individual consistently accepting or rejecting significantly more often than other members of the panel. In only one interesting case, shown in Table 17-5, was there an instance where two jars were rejected by the five member panel and one jar accepted by all members of the panel. This sample had been irradiated at $0.1 \mathrm{Mr}$ and stored at $46 \mathrm{~F}$ for time equal to $2 \mathrm{X}$. The toxin assay results are arranged to show the number of toxic jars of each three tested efther undigested or trypsinized. It may be observed in these Tables that the total plate count rose quite rapidly to $5 \times 10^{8}$ or greater at storage periods equal to $1 / 2 \mathrm{X}$ in many cases. In some cases, but not all, there was a tendency for counts to be lower in 
the stored 1rradiated samples than in the unirradiated. The $\mathrm{pH}$ of the samples rose rapidly to above 7.0 and then to 7.6 to 8.0 . After $0.2 \mathrm{Mr}$ and storage at lower temperatures there was a tendency for some jars to remain at $\mathrm{pH} 6.7-6.9$, although parallel jars would reach $\mathrm{pH} 8.0$. The total counts per gram seem higher than might be expected on fish fillets. This may be explained by the fact that $40 \mathrm{gms}$ of plugs cut from fillets have a much greater surface area exposed per gram than would a whole fish fillet. Some total counts were compared anaerobically and aerobically and it appears that at least $90 \%$ of the total aerobic count is composed of obligate aerobes and therefore would be growing on the surface of the fish.

The toxin assay results are summarized in Tables 17-14 to 17-17. These Tables are arranged to show storage temperature, irradiation dose, storage time, fraction or multiple of $\mathrm{X}$ and the result of the toxin assays. At $50 \mathrm{~F}$ (Table 17-14) no toxin was found after 16 days (2X) with either the $10^{2}$ or $10^{4}$ inoculum level in the unirradiated samples. After $0.1 \mathrm{Mr}$ no toxin was found after 6 and 12 days $(1 / 2, X)$ with efther inculum leve1; at 24 days toxin was found in one of three jars with the $10^{2}$ inoculum and no toxin was found at the $10^{4}$ inoculum. After $0.2 \mathrm{Mr}$ irradiation, toxin was found in one of three jars of the $10^{4}$ inoculum after 10 days $(1 / 2 \mathrm{X})$. This toxin was apparent only following trypsin digestion. No toxin was found after 10 days with the $10^{2}$ inoculum. After 20 and 40 days $(X, 2 X)$ all jars were toxic with either inoculum leve1 in the untrypsinized and trypsinized state. 
At $46 \mathrm{~F}$ (Table 17-14) no toxin was detected in unirradiated samples after 6,12 and 24 days $(1 / 2 \mathrm{X}, \mathrm{X}, 2 \mathrm{X})$ or in $0.1 \mathrm{Mr}$ samples after 6,13 , and 26 days $(1 / 2 X, X, 2 X)$ with either a $10^{6}$ or $10^{4}$ inoculum level. After $0.2 \mathrm{Mr}$ irradiation no toxin was found after 12 days $(1 / 2 \mathrm{X})$ with either a $10^{6}$ or $10^{4}$ inoculum. After 24 and 50 days $(x, 2 x)$ toxin was found in one of three jars with the $10^{6}$ inoculum, but no toxin was found at these time intervals with the $10^{4}$ inoculum.

Tables $17-15$ and $17-16$ show the results of toxin assays on samples inoculated with $10^{6}$ or $10^{4}$ spores stored at $42 \mathrm{~F}$ and $40 \mathrm{~F}$. In no case was toxin detected after storage times of $1 / 2 \mathrm{X}, 3 / 4 \mathrm{X}, \mathrm{X}, 1 \mathrm{1} / 2 \mathrm{X}$ and $2 \mathrm{X}$ in either unirradiated samples, or samples irradiated at $0.1 \mathrm{Mr}$ or $0.2 \mathrm{Mr}$.

Table 17-17 shows the results of toxin assays in haddock inoculated with $10^{6}$ or $10^{4}$ spores of the Beluga strain produced at $50 \mathrm{~F}$. No toxin has been detected in samples stored at $42 \mathrm{~F}$ or $40 \mathrm{~F}$ after $3 / 4 \mathrm{X}$, $\mathrm{X}, 11 / 2 \mathrm{X}$ and $2 \mathrm{X}$ storage times in unirradiated samples or. samples receiving either $0.1 \mathrm{Mr}$ or $0.2 \mathrm{Mr}$ irradiation.

The fallure to find toxin in haddock inoculated with either $10^{6}$ or $10^{4}$ spores per gram irradiated at either $0.1 \mathrm{Mr}$ or $0.2 \mathrm{Mr}$ and stored at $42 \mathrm{~F}$ or $40 \mathrm{~F}$ for twice the maximum storage life appears to be a quite favorable result and suggests that in haddock there should be no health hazard due to transportation and storage at these temperatures or at any temperature below $40 \mathrm{~F}$. In this test no difference was found in the behavior 
of spores produced at $85 \mathrm{~F}$ and at $50 \mathrm{~F}$.

At $46 \mathrm{~F}$ the results appear quite favorable also since no toxin has been found up to twice the maximum storage life of samples inoculated with $10^{6}$ or $10^{4}$ spores per gram and irradiated at $0.1 \mathrm{Mr}$. At $0.2 \mathrm{Mr}$ irradiation toxin was found in one of three replicate samples inoculated with $10^{6}$ at the maximum storage life and twice the maximum storage life. However, no toxin was found in samples inoculated with $10^{4}$ spores per gram and stored for twice the maximum storage life. It is the feeling of this group that negative results with an inoculum level of $10^{4}$ spores per gram for twice the maximum storage life will be interpreted as satisfactory evidence of the absence of health hazard even though occasional toxin production may be found earlier with a challenge dose of $10^{6}$ spores per gram.

The data obtained at $50 \mathrm{~F}$ storage are somewhat less favorable. No toxin was found with either the $10^{4}$ or $10^{2}$ spore per gram inoculum in unirradiated samples stored for twice the maximum storage life. After $0.1 \mathrm{Mr}$ irradiation no toxin was found at maximum storage Iife, although one of three samples of the $10^{2}$ inoculum level was toxic after twice the maximum storage life. After $0.2 \mathrm{Mr}$ irradiation with the $10^{4}$ inoculum. level one of three samples was toxic at half the maximum storage Iffe and all samples were toxic at maximum storage life and twice the maximum storage 1ife. In evaluating these results, we must bear in mind the rigourous criterion used In establishing the maximum storage life, that is the complete rejection of samples by an untrained panel based on odor. It has been 
observed many times in our examination of jars that samples accepted on the basis of odor had a very unattractive appearance due to slime or slight mold growth. In order to make our results comparable to those of the Gloucester laboratory, appearance was disregarded and rejection based only on odor. If appearance as we11 as odor were taken into consideration this might result in a reduction of the estimate of the maximum storage life particularly at the higher storage temperatures. At the practical level it would appear probable that the potential. consumer would take into account both appearance and odor; therefore, there is some degree of safety factor in the current method of estimating maximum storage life. 
A continuation of the cooperative study between the Bureau of Commercial Fisheries Laboratory at Gloucester and our laboratory is planned. The inoculated pack experiment on haddock has been completed and a similar experiment on cod is nearing completion. Once values for the maximal storage life ( $x$-values) on flounder are obtained from the BCF laboratory, the potential health hazard of $\mathrm{Cl}$. botulinum Type $\mathrm{E}$ will be determined in this product .

In the inoculated pack experiments, the general protocol recommended by the Ad Hoc advisory committee to the Atomic Energy Commission has been followed. A comparison of the health hazard aspect of $\mathrm{Cl}$. botulinum in low dose 1rradiated product to that in comparable unirradiated products seems to be the best approach to the botulinum problem.

The failure to detect toxin in unirradiated control haddock inoculated with $\mathrm{Cl}$. botulinum Type $\mathrm{E}$ and incubated at $50 \mathrm{~F}$ and below may merely be due to the shorter incubation time used. Unfortunately, the longest toxin assay time for the unirradiated product does not overlap the earlies time of toxin production in irradiated product. Therefore, the earliest occurrence of toxin in irradiated haddock might be the result of the longer incubation time used rather than any direct effect of irradiation. It would be desirable to repeat the haddock experiment and test for toxin 
in unfrradiated samples at time periods corresponding to the earliest appearance of toxin in Irradiated product.

It is concelvable that $\mathrm{Cl}$. botulinum Type $\mathrm{E}$ growth and toxin production may be inhibited by the normal spoilage microflora. Moreover, the proteolytic enzymes of such organisms or the normal autolytic enzymes of the fish itself may cause destruction of Type $E$ toxin as it is being formed. It would seem desirable to inoculate fresh haddock fillets with a known level of toxin and to assay for residual toxin after varing storage times at several low storage temperatures.

Further improvements in the mouse toxin assay procedure will be sought. The acetate buffer procedure appears to have greater sensitivity than the conventional phosphate buffer method and has been adopted for this reason. However, if Type $\mathrm{E}$ toxin is present, it usually can be detected by injection of the untrypsinized sample into mice. Nevertheless, incubated samples inoculated with Type $E$ are being assayed for toxin by the acetate method both undigested and trypsin digested.

The possible use of the gel diffusion technique to detect $\mathrm{Cl}$. botulinum toxins has been suggested. Work in $\mathrm{Dr} . \mathrm{H}$. Sugiyama's laboratory at the Food Research Institute has looked particularly promising. He has compared the mouse assay procedure to the 
gel diffusion method and found an excellent correlation (personal communication). His results are based on assays of smoked fish for Cl. botulinum Type $\mathrm{E}$ toxin. Work is being started in our laboratory to determine the sensitivity and applicabllity of the gel diffusion method for detecting Type $E$ toxin in incubated fresh fish fillets inoculated with Type E spores.

Another area of investigation that will be initiated is the determination of the low temperature outgrowth ability of spores of nonproteolytic Type B, Type F, and strains of Type C of marine origin. Type $B$ and $F$ isolates are being obtained from Dr. M. W. Eklund of the Bureau of Commercial Fisheries Laboratory at Seattle. Curde Type $\mathrm{C}$ cultures have been secured from Dr. B. Q. Ward of the Bureau of Commercial Fisheries Laboratory at Pascagoula, Mississippi. An attempt will be made to isolate pure Type C cultures and to test the ability of these isolates to grow and produce toxin in marine food product substrates at $50^{\circ} \mathrm{F}$. and below.

An experiment on cod fillets similar to that described in Phase XVII on haddock is in progress. As soon as the toxin assays are completed a supplementary report will be submitted.

During the current contract year the following papers were presented:

Segner, W. P. and C. F. Schmidt. Radiation resistance of spores of Clostridium botulinum Type E. Proc. International Symposium on 
Food Irradiation, Karlsruhe, Germany, June 6-10, 1966.

Segner, W.P., C. F. Schmidt and J. K. Boltz. Interaction of selected chemical additives with low dose radiation against spores of Clostridium botulinum Type E. Presented at the 26 th Annual Meeting, Institute of Food Technologists, Portland, Oregon. 
Ball, R. J. and W. Sellers. 1966. Improved Motility Medium App1. Microbiol., 14: 670-673.

Bott, T. L,, J. S. Deffner, E. Mc Coy, and E. M. Foster. 1966. Clostridium botulinum Type $\mathrm{E}$ in Fish from the Great Lakes. J. Bacteriol. 91: 919-924.

Breed, R. S., E. G. D. Murray, and N. R. Smtth. 1957. Bergey's Manual of Determinative Bacterfology. Williams and Wilkins, Company. p.1094..

Collins, C. H. 1964. Microbiological Methods. Butterworth, London. $330 \mathrm{p}$.

Cowan, S. T. and K. J. Steel. 1965. Manual for the Identification of Medical Bacteria. Cambridge University Press. 217 p.

Dack, G. M. 1956. Food Poisoning. The University of Chicago Press, Chicago. 251 p.

Dolman, C. E. 1964. Growth and metabolic activities of Clostridium botulinum types, p. 58. In K. H. Lewis and K. Cassel, (ed.), Botulism. Public Health Service Publication No. 999-FP-1, Cincinnati, Ohio.

Duff, J, T., G. G. Wright, and A. Yarinsky. 1956. Activation of Clostridium botulinum Type E toxin by trypsin. J. Bacteriol. 72: $455-460$. 
Erdman, I. E. Thatcher, F. S., and Mac Queen, K. F. 1961. Studies on the irradiation of microorganisms in relation to food preservation. II. Irradiation resistant mutants. Canad. Jour. Microbiol. 7: 207-215.

Folinazzo, J. F. and V. S. Troy. 1954. A Simple Bacteriological Medium for the Growth and Isolation of Spoilage Organisms from Canned Foods. Food Techno1. 8: 28-281.

Halstead, B, W. 1962. Blotoxications, Allergies, and other Disorders. p. 521-540. In GolBorgstrom, Fish as Food, Vol. II, Academic Press, New York.

Idzlak, E. S, and F. S. Thatcher. 1964. Some physiological aspects of mutants of Escherichia coli resistant to gamma irradiation. Can. J. Microbiol. 10: 683-697.

Johnson, J. G. , L. J. Kunz, W. Barron and W. H. Erving. 1966. Biochemical Differentiation of the Enterobacteriaceae with the aid of Lysine - Iron - Agar. App 1. Microbio1. 14: 212-217.

Pontefract, R. D. and F. S. Thatcher. 1965. A cytological study of normal and radiation - resistant Escherichia coli. Can. J. Microbio1. 11: 271-278.

Sakaguch 1, Genj1, and S. Sakaguch1. 1959. Studies on toxin production of Clostridium botulinum Type E. III. Characterization of toxin precursor J. Bacteriol. 78: 1-9. 
Shewan, J. M., G. Hobbs, and W. Hodgkiss. 1960. The Pseudomonas and Achromobacter Groups of Bacteria in the Spoilage of Marine White Fish. J. App1. Bacteriol. 23: 463-468.

Smith, D. T., N. F. Conant, and J. R. Overman. 1964. Miscellaneous bacteria of medical importance, p. 715-716. In Zinsser, Microbiology, Meredith Publishing Co., N.Y. 


\section{Table $1-1$}

Sporulation at $60 \mathrm{~F}$ in TPG medium and TPG medium plus $1 \%$ yeast extract.

$\begin{array}{ll}\text { Strain } & \text { Refractile spores per } \mathrm{ml} \times 10^{6} \\ \text { TPG } & \text { TPGY }\end{array}$

Beluga 14

51

$8 \mathrm{E}$

19

83

Alaska

10

49

M1nneapolis

Incubation time $=9$ days for maximum sporulation . 
Table 1-2

Sporulation at $50 \mathrm{~F}$ in TPG medium and TPG medium plus $1 \%$ yeast extract.

Strain

Beluga

$8 \mathrm{E}$

Alaska

Minneapolis
Refractile spores per $\mathrm{ml} \times 10^{6}$

TPG

TPGY

20

52

23

60

13

40

8

55

Incubation time $=18-20$ days for maximum sporulation. 
Table 5-1

butgrowth times of unheated and preheated spore inocula in undiluted ground haddock with respect to incubation temperature and radiation dose.

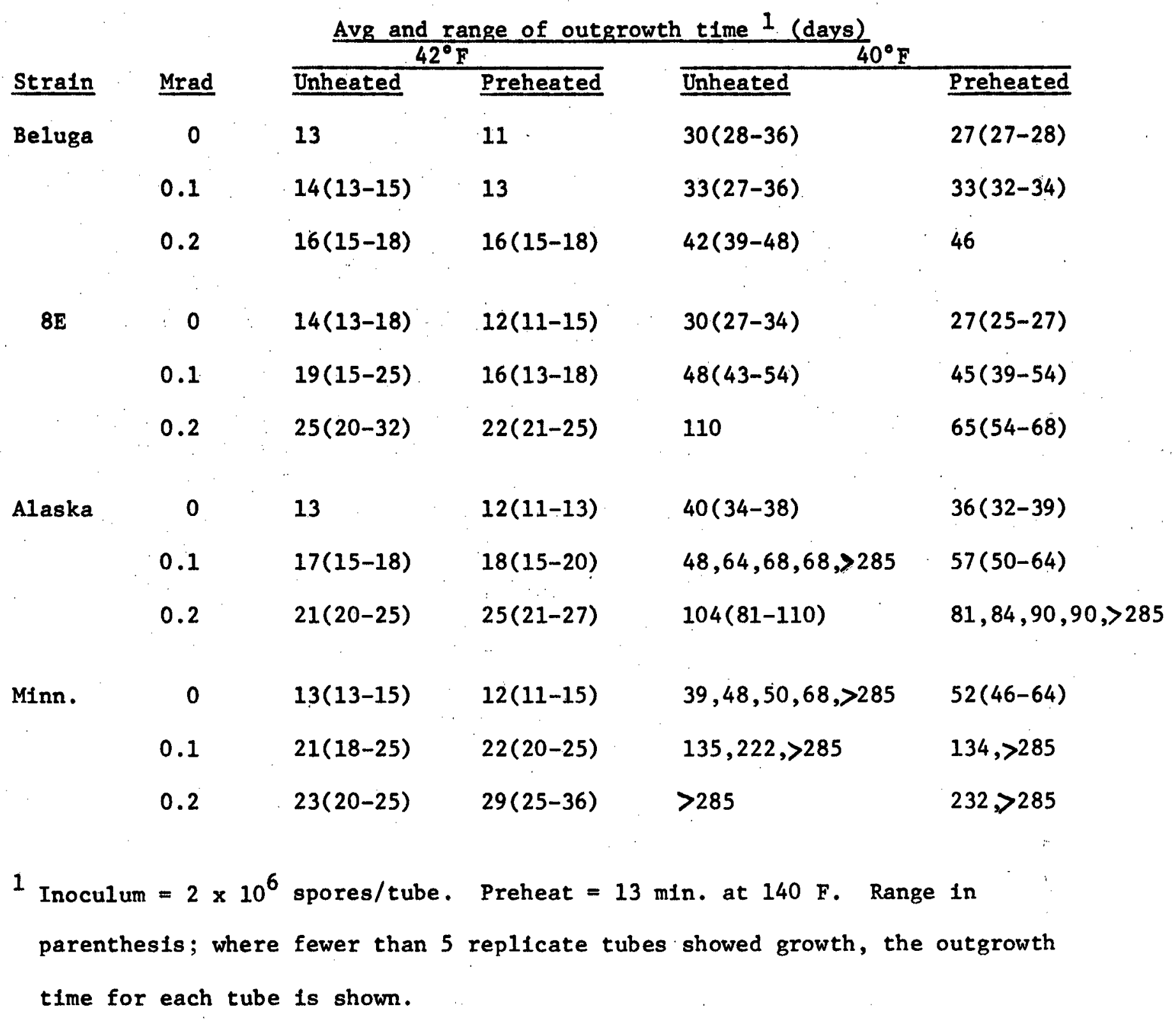


Table 5-2

Toxin formation at $46 \mathrm{~F}$ in ground haddock 1noculated with spores of the Beluga strain (Expt. 1).

\begin{tabular}{|c|c|c|c|c|c|}
\hline $\begin{array}{l}\text { Inc } \\
\text { TIme (Days) }\end{array}$ & Dose (Mrad) & Inoc 1 & $\mathrm{pH}$ & Toxin ${ }^{2}$ & $\begin{array}{l}\text { Total Aerobic } \\
\text { Count } \times 10^{6} \\
\end{array}$ \\
\hline \multirow[t]{4}{*}{10} & 0.1 & $10^{6}$ & 6.61 & $0 / 3$ & 17 \\
\hline & & $10^{4}$ & 6.59 & $0 / 3$ & 14 \\
\hline & 0.2 & $10^{6}$ & 6.58 & $0 / 3$ & 0.2 \\
\hline & & $10^{4}$ & 6.55 & $0 / 3$ & 2.1 \\
\hline \multirow[t]{4}{*}{24} & 0.1 & $10^{6}$ & 6.05 & $3 / 3$ & 100 \\
\hline & & $10^{4}$ & 6.14 & $0 / 3$ & 210 \\
\hline & 0.2 & $10^{6}$ & 6.36 & $1 / 3$ & 14 \\
\hline & & $10^{4}$ & 6.27 & $0 / 3$ & 220 \\
\hline \multirow[t]{3}{*}{60} & 0.1 & $10^{6}$ & - & - & - \\
\hline & & $10^{4}$ & 6.22 & $3 / 3$ & - \\
\hline & 0.2 & $10^{6}$ & - & $3 / 3$ & - \\
\hline & & $10^{4}$ & 6.25 & $1 / 3$ & - \\
\hline
\end{tabular}

1 Inoculum/gm and triplicate samples/variable.

2 Number tubes containing toxin/number of tube examined. 
Table 5-3

Toxin formation at $42 \mathrm{~F}$ in ground haddock inoculated with spores of the Beluga strain (Expt. 1).

Inc

Ime (days) Dose (Mrad) Inoc ${ }^{1}$ pH Toxin $\begin{aligned} & \text { Total Aerobic } \\ & \text { Count } \times 10^{6}\end{aligned}$

17

0.1

$10^{6}$

6.30

$0 / 3$

50

$10^{4} \quad 6.26 \quad 0 / 3 \quad 50$

$0.2 \quad 10^{6}$

$10^{6} \quad 6.36 \quad 0 / 3$

7.5

$10^{4}$

6.42

$0 / 3$

1.8

34

$\begin{array}{llll}0.1 & 10^{6} & 6.09 & 3 / 3\end{array}$

$10^{4}$

6.04

$0 / 3$

$0.2 \quad 10^{6}$

6.18

$2 / 3$

40

$10^{4}$

$6.120 / 3$

44

40

$$
\begin{array}{ll}
0.1 & 10^{6} \\
& 10^{4} \\
0.2 & 10^{6}
\end{array}
$$$$
10^{6}
$$$$
6.14 \quad 3 / 3
$$$$
110
$$$$
10^{4}
$$$$
6.04 \quad 0 / 3
$$$$
10^{6}
$$

6.10

$3 / 3$

110

$10^{4}$

6.1

$0 / 3$

54

1 Inoculum/gm.

2 Result not determined. 
Table 5-4

Toxin formation at $40 \mathrm{~F}$ in ground haddock Inoculated with spores of the Beluga strain (Expt. 1).

Inc

Time

30

Dose (Mrad)

Inoc ${ }^{1}$

pH Toxin

Total Aerobic

0.1

$10^{6}$

$6.13 \quad 1 / 3$

117

10

6.02

$0 / 3$

149

0.2

$10^{6}$

6.41

$0 / 3$

28

$10^{4} \quad 6.40 \quad 0 / 3$

16

40

$$
0.1
$$

$10^{6}$

6.05

$3 / 3$

110

$10^{4}$

5.93

$0 / 2$

130

0.

$$
10^{6}
$$

6.12

$3 / 3$

1.4

$10^{4}$

$6.120 / 3$

1.8

60

0.1

$10^{6}$

$-2$

$10^{4}$

6.16

$.0 / 3$

0.2

$10^{6}$

$10^{4}$

6.22

$0 / 3$

1 Inoculum/gm .

2 Result not determined. 
Table 5-5

Toxin formation at $46 \mathrm{~F}$ in ground haddock inoculated with spores of the Beluga strain (Expt. 2).

Inc

Time (days)

11

15

47

1 Inoculum/gm.

2 Result not determined.

0.2

0.1

0.2

0.1

0.2
Total Aerobic

Inoc ${ }^{1}$ pH Toxin

$10^{6} \quad 6.72 \quad 3 / 3$

$6.70 \quad 0 / 3$

$-2$

114

110

$6.35 \quad 2 / 2$

$0 / 3$

9.3

$\begin{array}{ll}6.53 & 0 / 3 \\ 6.48 & 0 / 3\end{array}$

7.6

$$
\begin{aligned}
& 10^{6} \\
& 10^{4}
\end{aligned}
$$

6.48

$10^{6}$
$10^{4}$

$\begin{array}{ll}- & 3 / 3 \\ 6.56 & 3 / 3\end{array}$

$-$

$10^{6}$

6.22

$3 / 3$
$0 / 3$

270

$10^{6}$
$10^{4}$

6.34
6.43

$1 / 3$

$0 / 3$

150

80

35

$\begin{array}{lll}106 & - \\ 10^{4} & -\end{array}$

$10^{6}$

104

6.49

-

$10^{6}$

6.18

6.28

$3 / 3$

$3 / 3$
-

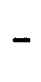


Table 5-6

Toxin formation at $42 \mathrm{~F}$ in ground haddock inoculated with spores of the Beluga strain (Expt. 2).

thic

Time (days)

Dose (Mrad)

Inoc 1

pH Toxin

Total Aerobic

15

0

$10^{6}$
$10^{6}$

$6.71 .3 / 3$

$6.780 / 3$

$-2$

0.1

$10^{6}$
$10^{4}$

$6.37 \quad 0 / 2$

$-$

0.2

$10^{6}$
$10^{4}$

6.40

$0 / 3$

170

130

21

$\begin{array}{llccc}0 & 10^{6} & 6.73 & - & 340\end{array}$

0.1

$10^{6}$

6.24

$2 / 3$

210

104

$6.27 \quad 0 / 2$

410

0.2

$10^{6}$

6.34
6.38

$0 / 3$

85

$10^{4}$

$0 / 3$

310

70

0
0.1
0.2
mined.

$10^{6}$
$10^{4}$

$-$

$2 / 3$

6.06

$1 / 3$

6.23

$0 / 3$

6.19
6.98

$0 / 3$
$0 / 3$

1 Inoculum/gm .

2 Result not determined. 


\section{Table 5-7}

Toxin formation at $40 \mathrm{~F}$ in ground haddock inoculated with spores of the Beluga strain (Expt. 2).

Inc

Time (days)

20

25

31

$$
\begin{array}{r}
0 \\
0.1 \\
0.2
\end{array}
$$

Inoc ${ }^{1}$

$10^{6}$

$10^{4}$

$10^{6}$

$10^{4}$

$10^{6}$

$10^{4}$

$10^{6}$

$10^{4}$

$10^{6}$

$10^{4}$

$10^{6}$
$10^{4}$

$10^{6}$

$10^{4}$

$10^{6}$

$10^{4}$

$10^{6}$

$10^{4}$
Toxin

$3 / 3$

$0 / 3$

$2 / 3$

$0 / 2$

$3 / 3$

$0 / 2$

$3 / 3$

$0 / 3$

$3 / 3$

$0 / 2$

$3 / 3$

$0 / 2$

$3 / 3$

$0 / 3$

$3 / 3$

$0 / 3$

$3 / 3$

$0 / 3$

1 Inoculum/gm. 


\section{Table 5-8}

Toxin formation at $46 \mathrm{~F}$ in ground cod inoculated with spores of the Beluga strain.

Inc

Time (days)

9

15

26

32

0
0.1
0.2

Dose (Mrad)

0

0.1

0.2

0

0.1

0.2

0

0.1

0.2

$\frac{10^{6} \text { Inoc* }}{\text { Toxin }} \cdot \frac{10^{4} \text { Inoc* }}{\text { Toxin }}$

$2 / 2$

7.04

$1 / 2$

7.06

$3 / 3$

6.72

$0 / 3$

6.73

$1 / 3$

6.73

$0 / 3$

6.71

$3 / 3$

6.87

$1 / 3$

6.96

$2 / 2$

6.59

$0 / 3$

6.64

$0 / 3$

6.74

$0 / 3$

6.63

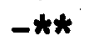

$3 / 3$

$1 / 3$

6.59

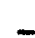

$-$

$3 / 3$

6.71

$3 / 3$

6.45

$-\quad-\quad 0 / 3$

6.55

* Inoculum/gm.

** Result not determined. 


\section{Table 5-9}

Toxin formation at $42 \mathrm{~F}$ in ground cod Inoculated with spores of the Beluga straln.

Inc

Time (days)

14

22

32

47

$$
\begin{aligned}
& 0.1 \\
& 0.2
\end{aligned}
$$

0.1

0.2

0.1

0.2

0

0.1

0.2

$\frac{10^{6} \text { Inoc* }}{\text { Toxin }} \quad \frac{10^{4} \text { Inoc* }}{\text { Toxin }}$

$3 / 3$

6.72

$0 / 3$

7.12

$1 / 2$

6.76

$0 / 3$

6.81

$1 / 3$

6.81

$0 / 3$

6.81

$-* *$

$0 / 3$

7.08

$2 / 2$

6.69

$0 / 2$

6.65

$0 / 3$

6.71

$0 / 3$

6.72

$3 / 3$

$3 / 3$

6.76

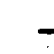

$-$

$0 / 3$

6.85

$-\quad-\quad 0 / 3$

6.35

- $\quad-$

$0 / 3$

6.50

* Inoculum/gm.

** Result not determined. 
Table 5-10

Toxin formation at $40 \mathrm{~F}$ in ground cod inoculated with spores of the Beluga strain.

Inc

Iime (Days).

20

25

31

40
0
0.1
0.2

$\frac{{ }_{3 / 3}^{106 \text { Inoc* }}}{\text { Toxin }} \frac{10^{4} \text { Inoc* }}{0 / 3}$

$2 / 3$

$0 / 3$

$1 / 3$

$0 / 3$

$3 / 3$

$0 / 3$

$2 / 3$

$0 / 3$

$0 / 3$

$0 / 3$

$3 / 3$

$0 / 3$

$2 / 3$

$0 / 3$

$0 / 3$

$0 / 3$

$2 / 3$

$0 / 3$

$3 / 3$

$0 / 3$

$3 / 3$

$0 / 3$

* Inoculum/gm. 
Table 5-11

Summary of toxin assay results of ground haddock inoculated with spores of the Beluga strain. 1

\begin{tabular}{|c|c|c|c|c|c|}
\hline \multirow[b]{3}{*}{$\operatorname{Temp}^{\circ} \mathrm{F}$} & \multirow{3}{*}{$\begin{array}{r}\text { Dose } \\
\text { (Mrad) } \\
\end{array}$} & \multicolumn{4}{|c|}{ Incubation Time (days) } \\
\hline & & \multicolumn{2}{|c|}{106 Inoc } & \multicolumn{2}{|c|}{$10^{4}$ Inoc } \\
\hline & & No Toxin & Toxin & No Toxin & Toxin \\
\hline \multirow[t]{3}{*}{46} & 0 . & 10 & 11 & 11 & 15 \\
\hline & 0.1 & 10 & 11 & 24 & 47 \\
\hline & 0.2 & 11 & 15 & 24 & 47 \\
\hline \multirow[t]{3}{*}{42} & 0 & -2 & 15 & 21 & 70 \\
\hline & 0.1 & 15 & 21 & 70 & - \\
\hline & 0.2 & 21 & 34 & 70 & - \\
\hline \multirow[t]{3}{*}{40} & 0 & - & 20 & 31 & - \\
\hline & 0.1 & - & 20 & 60 & - \\
\hline & 0.2 & - & 20 & 60 & - \\
\hline
\end{tabular}

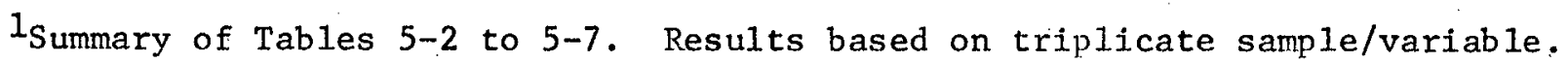
Non-toxic samples were negative undigested and with trypsin digestion by the phosphate and the acetate buffer procedures.

2 Result not determined.
} 
Table 5-12

Summary of toxin assay results of ground cod inoculated with spores of the Beluga strain. 1

\begin{tabular}{|c|c|c|c|c|c|}
\hline \multirow{3}{*}{$\operatorname{Temp}^{\circ} \mathrm{F}$} & \multirow{3}{*}{$\begin{array}{c}\text { Dose } \\
\text { (Mrad) }\end{array}$} & \multicolumn{4}{|c|}{ Incubation Time (days) } \\
\hline & & \multicolumn{2}{|c|}{106 Inoc } & \multicolumn{2}{|c|}{$10^{4}$ Inoc } \\
\hline & & No Toxin & Toxin & No Toxin & Toxin \\
\hline \multirow[t]{3}{*}{46} & 0 & -2 & 9 & - & 9 \\
\hline & 0.1 & - & 9 & 15 & 31 \\
\hline & 0.2 & - & 9 & 32 & - \\
\hline \multirow[t]{3}{*}{42} & 0 & $\therefore$ & 14 & 47 & - \\
\hline & 0.1 & - & 14 & 47 & - \\
\hline & 0.2 & 22 & 32 & 47 & - \\
\hline \multirow[t]{3}{*}{40} & 0 & - & 20 & 40 & - \\
\hline & 0.1 & - & 20 & 40 & - \\
\hline & 0.2 & - & 20 & 40 & - \\
\hline
\end{tabular}

1 Summary of Tables 8-10. Results based on triplicate samples/variable. Non-toxic samples were negative undigested and with trypsin digestion by the phosphate and acctate buffer procedures.

2 Result not determined. 
Table 5-13

Comparative outgrowth times with incubation at 40 and $38 \mathrm{~F}$ of spores produced at 85 F to those produced at low temperatures.

\begin{tabular}{|c|c|c|c|c|c|}
\hline \multirow{2}{*}{$\operatorname{Temp}^{\circ} \mathrm{F}$} & Mn & \multirow{2}{*}{ Test } & \multicolumn{3}{|c|}{ Avg and range of outgrowth time 1 (days) } \\
\hline & Mrad & & $85^{\circ} \mathrm{F}$ Spores & $50^{\circ} \mathrm{F}$ Spores & $46^{\circ} \mathrm{F}$ Spores \\
\hline 40 & 0 & $\begin{array}{l}1 \\
2\end{array}$ & $\begin{array}{l}20(18-21) \\
21(19-24)\end{array}$ & $\begin{array}{l}15 \\
15\end{array}$ & $\begin{array}{l}15 \\
15\end{array}$ \\
\hline & 0.1 & $\begin{array}{l}1 \\
2\end{array}$ & $\begin{array}{l}23(21-25) \\
26(25-27)\end{array}$ & $\begin{array}{l}18(17-18) \\
19(17-21)\end{array}$ & $\begin{array}{l}20(18-21) \\
23(21-24)\end{array}$ \\
\hline & 0.2 & $\begin{array}{l}1 \\
2\end{array}$ & $\begin{array}{l}28(26-31) \\
33(31-35)\end{array}$ & $\begin{array}{l}23(20-31) \\
21(17-26)\end{array}$ & $\begin{array}{l}25(21-35) \\
23(21-25)\end{array}$ \\
\hline 38 & 0 & $\begin{array}{l}1 \\
2\end{array}$ & $\begin{array}{l}109(59-171) \\
171,171,>200\end{array}$ & $\begin{array}{l}60(49-74) \\
80,80,87,>200\end{array}$ & $\begin{array}{l}54(40-66) \\
95(49-171)\end{array}$ \\
\hline & 0.1 & $\begin{array}{l}1 \\
2\end{array}$ & $\begin{array}{l}129(120-131) \\
180,180,180,>200\end{array}$ & $\begin{array}{l}60(49-100) \\
131,131,171,171,>200\end{array}$ & $\begin{array}{l}75(52-100) \\
177(171-186)\end{array}$ \\
\hline & 0.2 & $\begin{array}{l}1 \\
2\end{array}$ & $\begin{array}{l}186,>200 \\
186,186,186,>200\end{array}$ & $\begin{array}{l}158(131-186) \\
>200\end{array}$ & $\begin{array}{l}139(131-171) \\
165(141-171)\end{array}$ \\
\hline
\end{tabular}

1 Average and range of five tube replicate sets. Where fewer than five tubes gave outgrowth, the outgrowth time for each tube is shown. 
Table 7-1

Toxin assay results on samples of ground, unsteamed haddock or cod which were toxin negative by the phosphate buffer-trypsin digestion procedure. 1

Substrate

Haddock

$\operatorname{cod}$

46

42

42

40

\section{Number Samples Toxic/Number Assayed Untrypsinized}

$$
0 / 22
$$

$3 / 22$

$0 / 46$

$2 / 46$

$0 / 11$

$0 / 11$

$5 / 30$

$3 / 30$

$3 / 33$

$4 / 33$

Totals $8 / 142$
$12 / 142$

1 Based on untrradiated and Irradiated samples inoculated w1th $2 \times 10^{6}$ spores/replicate tube of the Beluga strain.

2 Final concentration of sodium acetate ( $\mathrm{pH} 5.5$ ) equalled $0.25 \mathrm{M}$. Acetate samples were trypsinized after being held about 24 hours at $38 \mathrm{~F}$. 
Table 7-2

Comparative toxin assay results on samples of ground fish inoculated with spores of the Beluga strain and Incubated at $40 \mathrm{~F}$.

\begin{tabular}{|c|c|c|c|c|c|}
\hline \multirow[b]{2}{*}{ Substrate } & \multirow[b]{2}{*}{ Dose (Mrad) } & \multirow[b]{2}{*}{ Inoc $^{2}$} & \multicolumn{3}{|c|}{ Fraction of Samples Toxic $c^{1}$} \\
\hline & & & Untrypsinized & Acetate $^{3}$ & $\mathrm{~PB} 4$ \\
\hline \multirow[t]{4}{*}{ Haddock } & 0.1 & $10^{6}$ & $7 / 7$ & $7 / 7$ & $6 / 7$ \\
\hline & & 104 & $0 / 7$ & $0 / 7$ & $0 / 7$ \\
\hline & 0.2 & $10^{6}$ & $8 / 9$ & $9 / 9$ & $4 / 9$ \\
\hline & & $10^{4}$ & $0 / 7$ & $0 / 7$ & $0 / 7$ \\
\hline \multirow[t]{5}{*}{ Cod } & 0.1 & $10^{6}$ & $7 / 12$ & $9 / 12$ & $0 / 12$ \\
\hline & & $10^{4}$ & $0 / 12$ & $0 / 12$ & $0 / 12$ \\
\hline & 0.2 & $10^{6}$ & $2 / 12$ & $5 / 12$ & $0 / 12$ \\
\hline & & $10^{4}$ & $0 / 12$ & $0 / 12$ & $0 / 12$ \\
\hline & & Tota & $24 / 78$ & $30 / 78$ & $\alpha 78$ \\
\hline
\end{tabular}

1 Number tubes toxic/number tubes assayed.

2 Inoculum per gram of ground fish.

3 With pH 5.5 sodium acetate buffer and trypsin digestion for 3 hours at $98 \mathrm{~F}$.

4 With pH 6.2 phosphate buffer and trypsin digestion for one hour at $98 \mathrm{~F}$. 
Table 7-3

\begin{tabular}{|c|c|c|c|}
\hline \multirow[b]{2}{*}{$\begin{array}{l}\text { Irradiation } \\
\text { Dose (Mrad) } \\
\end{array}$} & \multirow[b]{2}{*}{ Inc. $\operatorname{Temp}^{\circ} \mathrm{F}$} & \multicolumn{2}{|c|}{ Incubation Time (days) } \\
\hline & & $\begin{array}{c}\text { Nonspecific } \\
\text { Toxicity Absent }\end{array}$ & $\begin{array}{c}\text { Nonspecific } \\
\text { Toxiclty Present }\end{array}$ \\
\hline \multirow[t]{4}{*}{0} & 50 & & 4 \\
\hline & 46 & & 6 \\
\hline & 42 & 8 & 11 \\
\hline & 40 & & 17 \\
\hline \multirow[t]{4}{*}{0.1} & 50 & 6 & 12 \\
\hline & 46 & 13 & 26 \\
\hline & 42 & 29 & 39 \\
\hline & 40 & 80 & \\
\hline \multirow[t]{4}{*}{0.2} & 50 & 40 & \\
\hline & 46 & 50 & \\
\hline & 42 & 80 & \\
\hline & 40 & 80 & \\
\hline
\end{tabular}


Table $7-4$

History of blended haddock samples assoclated directly or indirectly

with cultures isolated from mice showing nonspecific botulinal symptoms.

Inc

Proteus

vulgar1s $480-2$

$480-25$

7-11

7-12

8-14

Inc $\operatorname{Temp}^{\circ} \mathrm{F}$

Time (days)

Mrad

50

15

0

16

0

0

Proteus

vulgaris $\quad 31-1$

317-20

46

12

15

26

0

61-5

0.1

Proteus

$$
\text { morgani1 9-16 }
$$

50

15

0

480-21-1

481-22

Proteus

rettgeri $\quad 480-25-2$

15

0

Aerobacter

aerogenes 31-2

46

12

0

61-6

26

0.1

Actinobacillus

480-24

50

15

0

Enterococcus

8-13

50

16

0

9-15

480-25-1

Erysipelothrix

314-17

46

15

0

316-19

317-20-1

Alcallgenes

481-22-1

50

15

0 
Table 7-5

Cultural characteristics of Erysipelothrix Insidiosa 1solated from mice showing nonspecific botulinal symptoms.

\section{Test}

Gram strain

( $\left.\mathrm{H}_{2} \mathrm{~S}\right)$ production

Indole

Catalase

Oxidase

Mot1lity.

Growth in air

Fermentation reactions :
Observation or Reaction

Thin, filamentous Gram positive rod positive (anaerobic)

negative

negative

negative

negative

microaerophilic

$\begin{array}{lc}\text { Xylose } & -* \\ \text { Dextrose } & + \\ \text { Maltose } & + \\ \text { Sucrose } & - \\ \text { Lactose } & + \\ \text { Rhamnose } & - \\ \text { Mannitol } & - \\ \text { Ducitol } & - \\ \text { Salcin } & - \\ \text { Raffinose } & -\end{array}$

Growth at $45^{\circ} \mathrm{C}\left(113^{\circ} \mathrm{F}\right)$

Growth at $10^{\circ} \mathrm{C}\left(50^{\circ} \mathrm{F}\right)$

* Indicates negative reaction 
Table 13-1

Comparative radfation resistance of spores of the Beluga strain in haddock homogenate to TPG medium.

$\begin{array}{lccc}\text { Substrate } & \frac{D \text { Exponential }}{\text { Haddock }} & \frac{106 \text { inactivation }}{(\text { Erad) }} & \begin{array}{c}\text { Lag-value } \\ \text { (Mrad) }\end{array} \\ \text { TPG } & 0.21 & 0.23 & 0.39 \\ 0.21 & 0.25 & 0.45\end{array}$


Table 16-1

Effect of length of incubation at $85 \mathrm{~F}$ on the yleld and germination of spores of the Beluga strain produced from the first generation of 0.8 Mrad survivors.

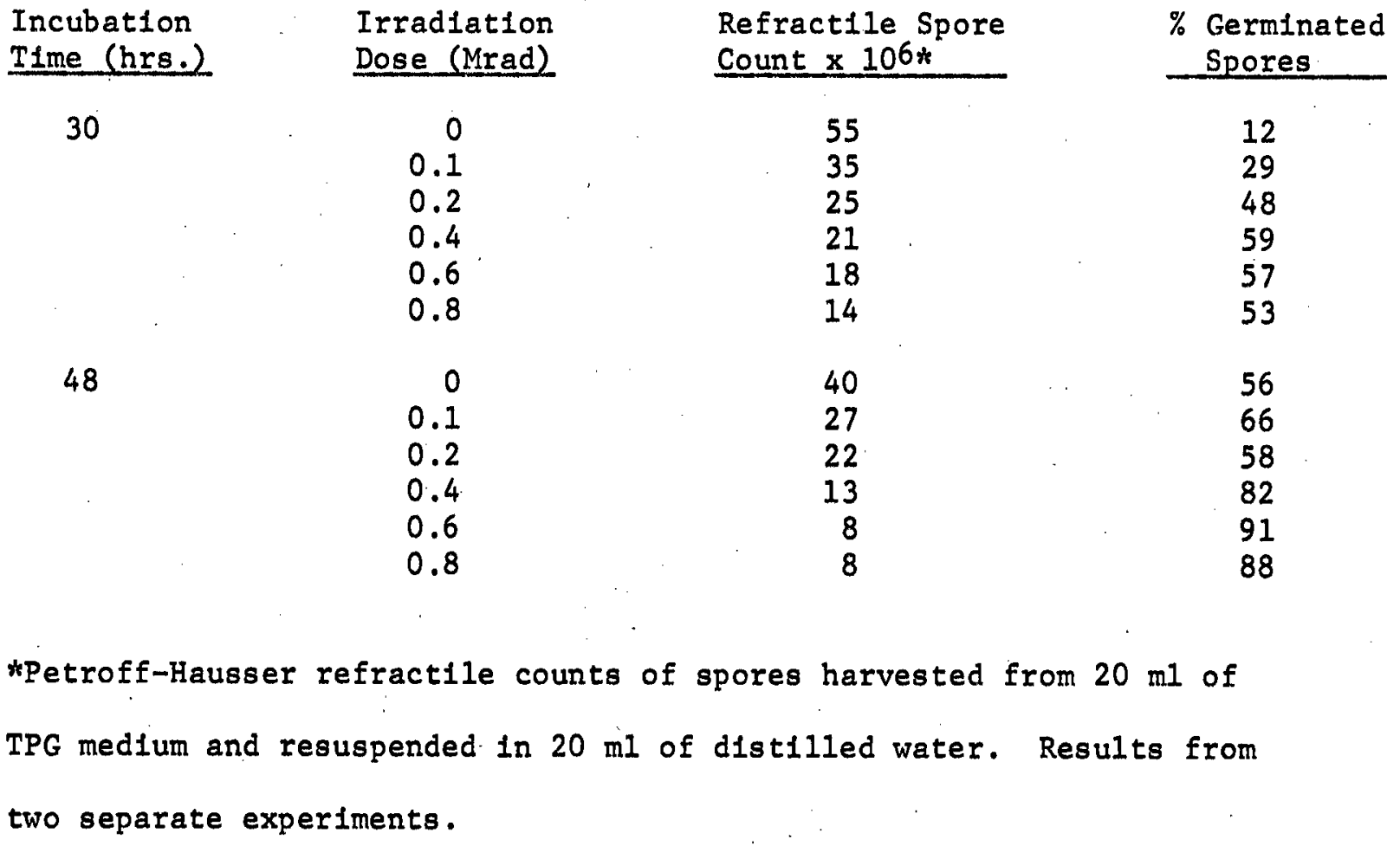


Table 16-2

Germination of spores of the Beluga strain at $34 \mathrm{~F}$ when held overnight In the sporulation medium.

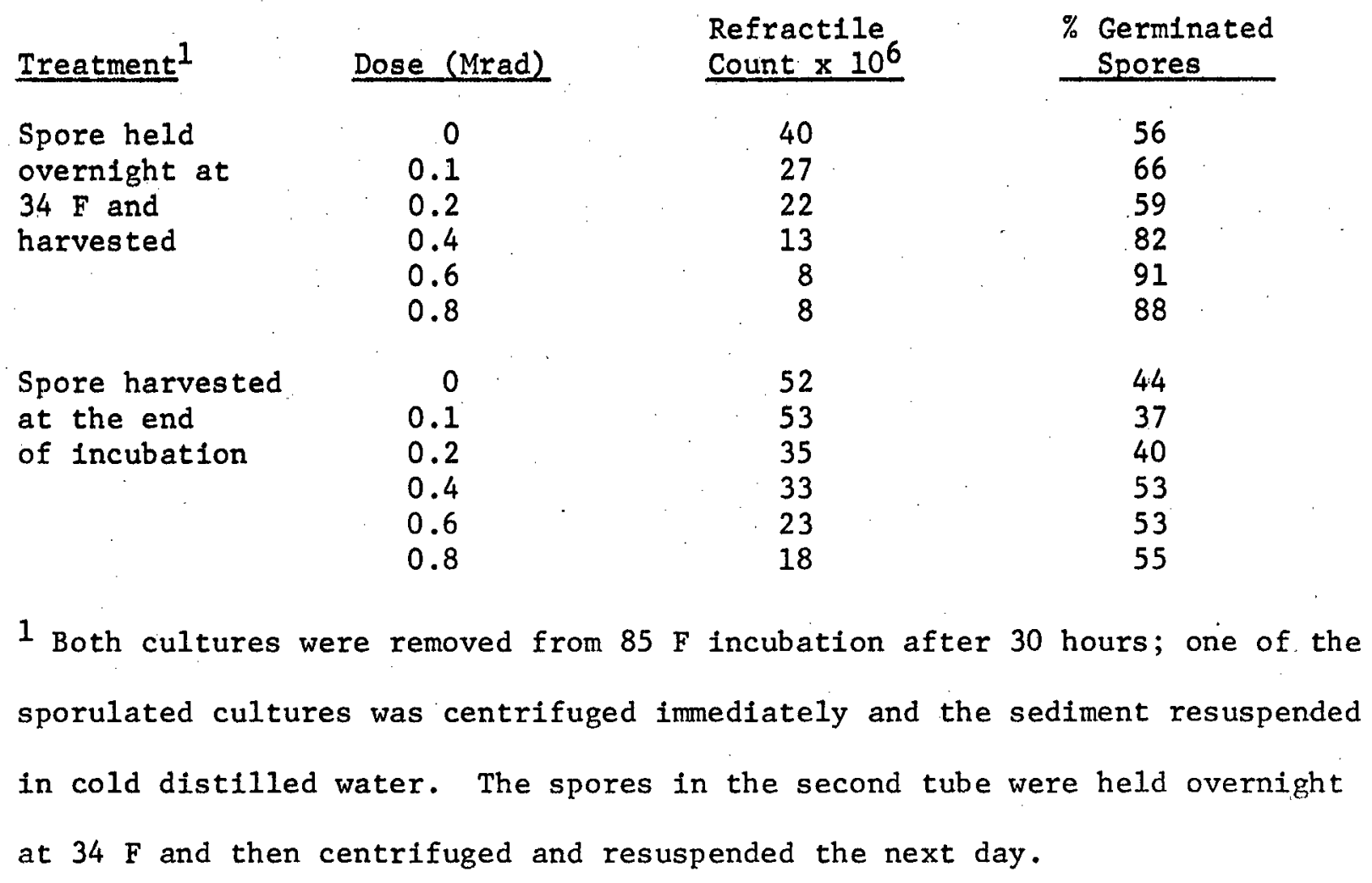


Table 16-3

Yield and percent germination of spore suspensions produced from unirradiated and irradiated combinations of spore inoculum and TPG medium.

Treatment Combination 1 Medium Irradiated Inoculum Irradiated

no

yes

yes

no no

yes

no

yes
No. Refractile Spores $\times 10^{6}$ Obtained

$55^{*}$

18

14

44
\% Germinated Spores

$12 *$

55

73

37

1 TPG medium or spore inoculum irradiated at 0.8 Mrad.

* Count on suspension produced from inoculum of the parent spore suspension. 
Table 16-4

Yleld and viability of spores of the Beluga strain in consecutive suspensions produced from 0.8 Mrad Irradiation survivors.

\begin{tabular}{|c|c|c|c|c|}
\hline $\begin{array}{c}\text { Spore } \\
\text { Suspension }\end{array}$ & $\begin{array}{l}\text { Refract1le } \\
\text { Count } \times 10^{6} \\
\end{array}$ & $\begin{array}{l}\text { \% Germinated } \\
\text { Spores } \\
\end{array}$ & $\begin{array}{l}\text { V1able } \\
\text { Count } \times 10^{6} \\
\end{array}$ & $\begin{array}{l}\% \text { Viab1lity of } \\
\text { Refractlle Count }\end{array}$ \\
\hline s & 370 & 16 & 340 & 92 \\
\hline$s_{1}$ & 14 & 53 & 8.0 & 57 \\
\hline$s_{2}$ & 18 & 55 & 8.1 & 45 \\
\hline$s_{3}$ & 10 & 73 & 5.6 & 56 \\
\hline$s_{4}$ & 16 & 51 & 11.5 & 70 \\
\hline \multicolumn{5}{|c|}{$S=$ undiluted stock spore suspension. } \\
\hline \multicolumn{5}{|c|}{$\mathrm{s}_{1}=$ suspension produced from $0.8 \mathrm{Mrad}$ survivors that previous $1 \mathrm{y}$ had not been } \\
\hline
\end{tabular}


Table 16-5

Comparative outgrowth times of the parent and fourth generation radiation resistant spores of the Beluga strain at 42,40 , and $38 \mathrm{~F}$ In undlituted, steamed haddock.

$\underline{\operatorname{Temp}}{ }^{\circ} \mathrm{F}$

42

40

38
Avg and Range of Outgrowth TIme 1 (days) Parent

$16(15-18)$

24(19-39)

$82(60-104)$
$\mathrm{S}_{4}$

$28(25-30)$

$49(27-74)$

$130(104-160)$

1 Based on ten replicate tubes per variable and an inoculum of $2 \times 10^{6}$ spores/tube. 
Table 16-6

Percent 1rradiation survivors of spores of the Beluga strain in consecutive suspensions produced from 0.8 Mrad survivors.

Dose (Mrad)

\section{0}

0.1

0.2

0.4

0.6

0.8

\begin{tabular}{|c|c|c|c|}
\hline S & $\mathrm{s}_{1}$ & $\mathrm{~s}_{2}$ & S3 \\
\hline $\begin{array}{l}100 \\
71.4 \\
52.4 \\
16.2 \\
2.28 \\
0.19\end{array}$ & $\begin{array}{l}100 \\
50.7 \\
28.0 \\
4.4 \\
0.60 \\
0.056\end{array}$ & $\begin{array}{l}100 \\
57.3 \\
34.7 \\
13.3 \\
1.40 \\
0.140\end{array}$ & $\begin{array}{l}100 \\
29.8 \\
10.8 \\
3.0 \\
0.54 \\
0.035\end{array}$ \\
\hline
\end{tabular}

* Parent spore suspension, deslgnated S. 
Table 16-7

Radiation resistance values of spores of the Beluga strain subjected to repeated 0.8 Mrad radiation.

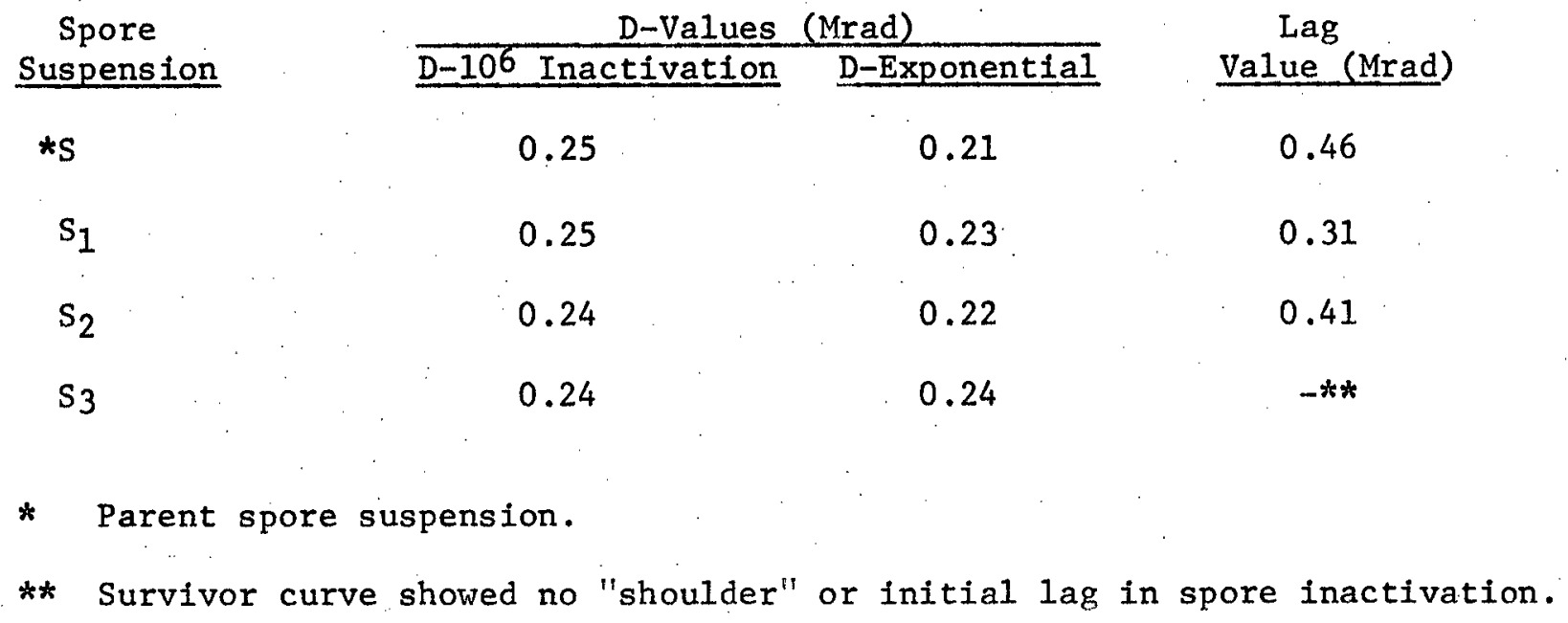


Table 16-8

Recovery counts and percent irradiation survivors of spores of the Beluga strain recycled three times at $0.8 \mathrm{Mrad}$.

Test 1

Dose (Mrad)

0

0.1

0.2

0.4

0.6

0.8

\begin{tabular}{rc}
\hline Survivors/g & $\%$ Survivors \\
\hline 74,000 & 100 \\
22,000 & 29.8 \\
8,000 & 10.8 \\
2,200 & 2.98 \\
400 & 0.54 \\
26 & 0.035
\end{tabular}

Test 2

\begin{tabular}{rc}
\hline Survivors/g & $\%$ Survivors \\
\hline 76,000 & 100 \\
12,000 & 16.2 \\
9,600 & 13.0 \\
1,000 & 1.35 \\
340 & 0.46 \\
24 & 0.032
\end{tabular}


Table 16-9

Loss of viability of spores of the Beluga strain produced form fourth generation 0.8 Mrad survivors when Inoculated Into TPG medium and held at $34 \mathrm{~F}$.

Sampling 1

Time (hrs.)

0

24

72
Viable Count $\times 10^{4} / \mathrm{ml}$ Recovered $70^{\circ} \mathrm{F}$ $85^{\circ} \mathrm{F}$

9.0

16

5.8

3.7

7.7

1 Spores of the 4 th generation Irradiation survivors were Inoculated into chilled TPG medium and held at $34^{\circ} \mathrm{F}$. Vlable counts were made at the sampling perlods shown. 


\section{Table 17-1}

Total plate counts on jar samples of haddock prior to and following 1rradiation.

\section{Total plate count per gram}

$\begin{array}{llll}\text { Day (1) } & \text { Exp. } 1 & \text { Exp. } 2 & \text { Exp. } 3 \\ \text { Tuesday } & 26 \times 10^{4} & 15 \times 10^{4} & 46 \times 10^{4} \\ \text { Wednesday } & 35 \times 10^{4} & 27 \times 10^{4} & 52 \times 10^{4} \\ \text { Thursday } & 41 \times 10^{4} & 36 \times 10^{4} & 73 \times 10^{4} \\ 0.1 \mathrm{Mr} & 21 \times 10^{2} & 19 \times 10^{2} & 11 \times 10^{2} \\ 0.2 \mathrm{Mr} & 16 \times 10^{2} & 10 \times 10^{2} & 7 \times 10^{2} \\ \begin{array}{l}\text { \% reduction } \\ 0.1 \mathrm{Mr}\end{array} & 99.4 & & \\ \% \text { reduction } & \vdots 9.6 & 99.4 & 99.8 \\ 0.2 \mathrm{Mr} & 99.6 & 99.6 & 99.9\end{array}$

(1) Fish filleted and shipped tced by alr freight on Monday . 
Table 17-2

Toxin production in haddock Inoculated with $10^{4}$ spores per gram, unfrradiated and Irradiated stored at $50 \mathrm{~F}$. Spores produced at $85 \mathrm{~F}$.

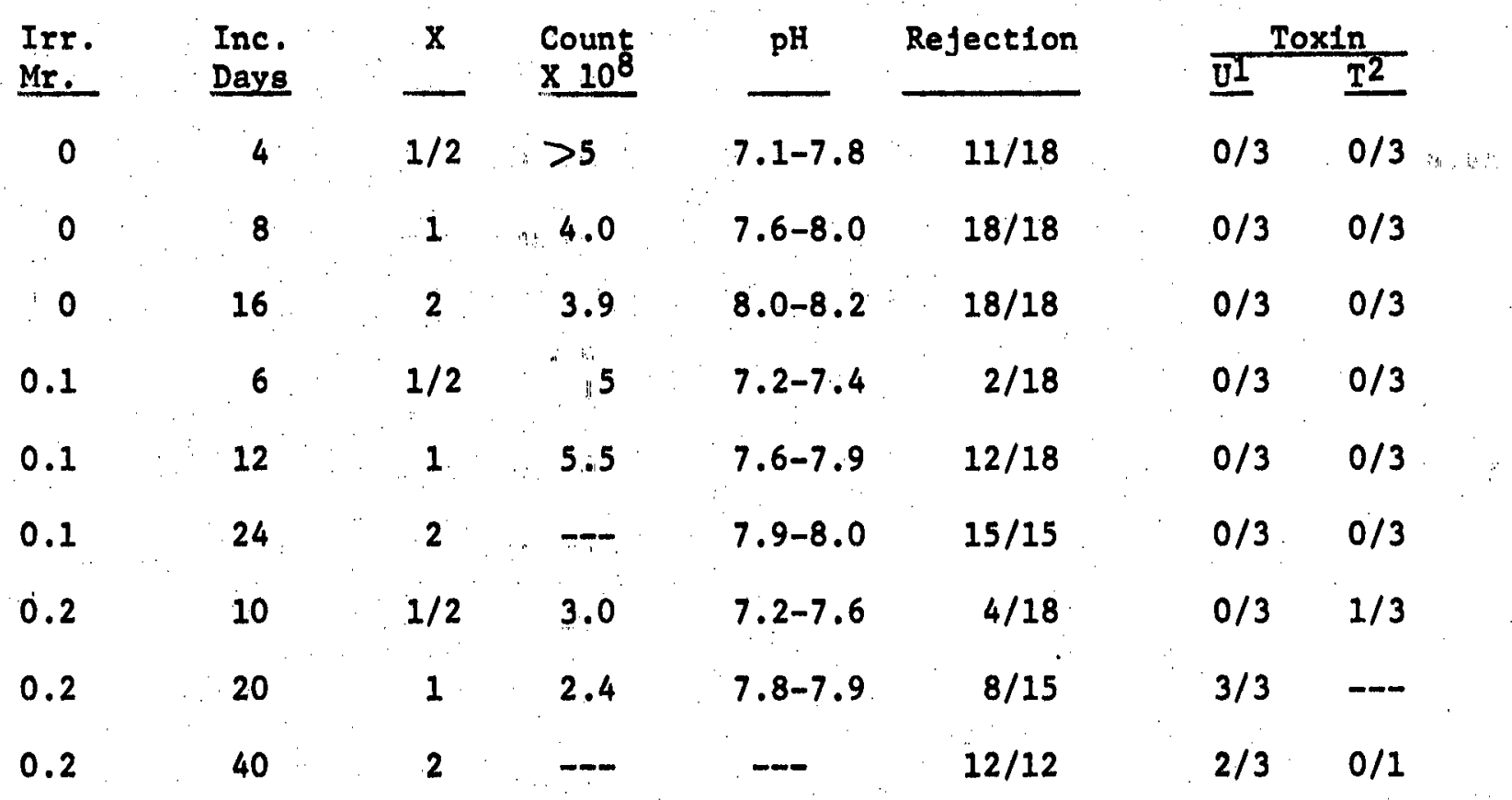

1 Untrypsintzed.

2 Trypsinized. 


\section{Table 17-3}

Toxin production in haddock Inoculated with $10^{2}$ spores per gram, unirradiated and Irradiated stored at $50 \mathrm{~F}$. Spores produced at $85 \mathrm{~F}$.

\begin{tabular}{|c|c|c|c|c|c|c|c|c|}
\hline Irr. & Inc. & $\mathrm{X}$ & Count & $\mathrm{pH}$ & Rejection & \multicolumn{3}{|c|}{ Toxin } \\
\hline Mr. & Days & & & & & $\underline{\mathbf{u}^{1}}$ & $T^{2}$ & \\
\hline 0 & 4 & $1 / 2$ & $>5$ & $7.3-7.4$ & $10 / 18$ & $0 / 3$ & $0 / 3$ & and \\
\hline 0 & 8 & 1 & 4.2 & $7.5-7.7$ & $18 / 18$ & $0 / 3$ & $0 / 3$ & \\
\hline 0 & 16 & 2 & -- & $7.9-8.0$ & $18 / 18$ & $0 / 3$ & $0 / 3$ & \\
\hline 0.1 & 6 & $1 / 2$ & $>5$ & $7.0-7.4$ & $0 / 18$ & $0 / 3$ & $0 / 3$ & \\
\hline 0.1 & 12 & 1 & $\ldots 7.5$ & $7.9-8.0$ & $2 / 18$ & $0 / 3$ & $0 / 3$ & $\Rightarrow$ \\
\hline 0.1 & 24 & 2 & $\pi=$ & $7.6-7.7$ & $15 / 15$ & $1 / 3$ & $0 / 3$ & \\
\hline 0.2. & 10 & $1 / 2$ & 3.6 & $7.0-7.4$ & $11 / 15$ & $0 / 3$ & $0 / 3$ & \\
\hline 0.2 & 20 & 1 & 5.6 & $7.9-8.0$ & $12 / 12$ & $2 / 3$ & $0 / 1$ & \\
\hline 0.2 & 40 & 2 & -- & --- & $12 / 12$ & $2 / 3$ & $0 / 1$ & \\
\hline
\end{tabular}

1 Untrypsintzed.

2 Trypsinized. 
Table 17-4

Toxin production in haddock inoculated with $10^{6}$ spores per gram unirradiated and irradiated stored at $46 \mathrm{~F}$. Spores produced at $85 \mathrm{~F}$.

\begin{tabular}{|c|c|c|c|c|c|c|c|}
\hline Irr. & Inc. & $\mathrm{X}$ & Count & $\mathrm{pH}$ & Rejection & & \\
\hline Mr. & Days & $\therefore$ & $\times 10^{8}$ & & & $\mathrm{U}^{\mathrm{I}}$ & $T^{2}$ \\
\hline 0 & 6 & $1 / 2$ & $>5$ & 7.4 & $15 / 18$ & $0 / 3$ & $0 / 3$ \\
\hline 0 & 12 & 1 & $>5$ & $7.9-8.1$ & $18 / 18$ & $0 / 3$ & $0 / 3$ \\
\hline 0 & 24 & 2 & -- & $8.0-8.1$ & $15 / 15$ & $0 / 3$ & $0 / 3$ \\
\hline 0.1 & 6 & $1 / 2$ & $>5$ & $7.1-7.3$ & $0 / 18$ & $0 / 3$ & $0 / 3$ \\
\hline 0.1 & 13 & 1 & 20 & $7.5-7.6$ & $1 / 18$ & $0 / 3$ & $0 / 3$ \\
\hline 0.1 & 26 & 2 & - & $7.7-8.0$ & $15 / 15$ & $0 / 3$ & $0 / 3$ \\
\hline 0.2 & 12 & $1 / 2$ & 19 & $7.2-7.4$ & $3 / 18$ & $0 / 3$ & $0 / 3$ \\
\hline 0.2 & 24 & 1 & 24 & $7.9-8.0$ & $9 / 15$ & $0 / 3$ & $1 / 3$ \\
\hline 0.2 & 50 & 2 & - & $7.7-8.3$ & $9 / 9$ & $1 / 3$ & $0 / 2$ \\
\hline
\end{tabular}

1 Untrypsinized.

2. Trypsinized. 
Table 17-5

Toxin production in haddock inoculated with $10^{4}$ spores per gram unirradiated and Irradiated stored at $46 \mathrm{~F}$. Spores produced at $85 \mathrm{~F}$.

\begin{tabular}{|c|c|c|c|c|c|c|c|}
\hline Irr. & Inc. & $\mathrm{x}$ & Count & $\mathrm{pH}$ & Rejection & & \\
\hline Mr. & & & & & & $U^{\perp}$ & $T^{2}$ \\
\hline 0 & 6 & $1 / 2$ & $>5$ & 7.4 & $15 / 18$ & $0 / 3$ & $0 / 3$ \\
\hline 0 & 12 & 1 & 50 & $7.9-8.1$ & $18 / 18$ & $0 / 3$ & $0 / 3$ \\
\hline 0 & 24 & 2 & - & $8.0-8.1$ & $18 / 18$ & $0 / 3$ & $0 / 3$ \\
\hline 0.1 & 6 & $1 / 2$ & $>5$ & $6.9-7.2$ & $2 / 18$ & $0 / 3$ & $0 / 3$ \\
\hline 0.1 & 13 & 1 & 21 & $7.5-8.0$ & $1 / 18$ & $0 / 3$ & $0 / 3$ \\
\hline 0.1 & 26 & 2 & - & $8.0-8.2$ & $10 / 15 *$ & $0 / 3$ & $0 / 3$ \\
\hline 0.2 & 12 & $1 / 2$ & 19 & $7.2-7.6$ & $3 / 18$ & $0 / 3$ & $0 / 3$ \\
\hline 0.2 & 24 & 1 & 22 & $7.7-8.0$ & $8 / 15$ & $0 / 3$ & $0 / 3$ \\
\hline 0.2 & 50 & 2 & - & $7.8-8.1$ & $9 / 9$ & $0 / 3$ & $0 / 3$ \\
\hline
\end{tabular}

1 Untrypsinized.

2 Trypsinized.

* one jar not rejected by 5 panel members. 
Table 17-6

Toxin production in haddock inoculated with $10^{6}$ spores per gram unirradiated and Irradiated stored at $42 \mathrm{~F}$. Spores produced at $85 \mathrm{~F}$.

\begin{tabular}{|c|c|c|c|c|c|c|c|}
\hline Irr. & Inc. & $\mathrm{X}$ & Count & $\mathrm{pH}$ & Rejection & & \\
\hline Mr. & Days & & $\underline{X 10^{8}}$ & & & $\mathrm{UI}$ & $\mathrm{T}^{2}$ \\
\hline 0 & 8 & $1 / 2$ & $>5$ & $6.9-7.6$ & $5 / 15$ & $0 / 3$ & $0 / 3$ \\
\hline 0 & 11 & $3 / 4$ & $>5$ & $7.5-7.9$ & $13 / 15$ & $0 / 3$ & $0 / 3$ \\
\hline 0 & 15 & 1 & 34 & $7.0-7.9$ & $17 / 18$ & $0 / 3$ & $0 / 3$ \\
\hline 0 & 22 & $11 / 2$ & 51 & $6.5-8.0$ & $18 / 18$ & $0 / 3$ & $0 / 3$ \\
\hline 0 & 29 & 2 & - & $7.9-8.0$ & $18 / 18$ & $0 / 3$ & $0 / 3$ \\
\hline 0.1 & 14 & $1 / 2$ & 0.7 & $6.8-7.2$ & $9 / 15$ & $0 / 3$ & $0 / 3$ \\
\hline 0.1 & 22 & $3 / 4$ & 2.4 & $6.6-7.4$ & $13 / 18$ & $0 / 3$ & $0 / 3$ \\
\hline 0.1 & 29 & 1 & 6.4 & $7.0-8.0$ & $10 / 12$ & $0 / 3$ & $0 / 3$ \\
\hline 0.1 & 46 & $11 / 2$ & 12 & $6.7-8.1$ & $18 / 18$ & $0 / 3$ & $0 / 3$ \\
\hline 0.1 & 60 & 2 & -- & $8.0-8.3$ & -- & $0 / 3$ & $0 / 3$ \\
\hline 0.2 & 18 & $1 / 2$ & 2.3 & $6.7-7.0$ & $10 / 18$ & $0 / 3$ & $0 / 3$ \\
\hline 0.2 & 27 & $3 / 4$ & 8.3 & $7.3-7.9$ & $12 / 15$ & $0 / 3$ & $0 / 3$ \\
\hline 0.2 & 36 & 1 & 5.2 & $6.9-8.1$ & $15 / 15$ & $0 / 3$ & $0 / 3$ \\
\hline 0.2 & 54 & $11 / 2$ & -- & $7.1-8.0$ & -- & $0 / 3$ & $0 / 3$ \\
\hline 0.2 & 80 & 2 & 12 & $8.1-8.4$ & $18 / 18$ & $0 / 3$ & $0 / 3$ \\
\hline
\end{tabular}

1 Untrypsinized.

2 Trypsintzed. 
Table 17-7

Toxin production in haddock inoculated with $10^{4}$ spores per gram unirradiated and Irradiated stored at $42 \mathrm{~F}$. Spores produced at $85 \mathrm{~F}$.

\begin{tabular}{|c|c|c|c|c|c|c|c|}
\hline Irr. & Inc. & $x$ & Count & $\mathrm{pH}$ & Rejection & \multicolumn{2}{|c|}{ Toxin } \\
\hline Mr. & Days & $\dot{m}$ & $\times 10^{\circ}$ & & & U1 & $T^{2}$ \\
\hline 0 & 8 & $1 / 2$ & $>5 . \cdots$ & $7.0-7.5$ & $7 / 15$ & $0 / 3$ & $0 / 3$ \\
\hline 0 & 11 & $3 / 4$ & $>5$ & $7.5-7.7$ & $12 / 15$ & $0 / 3$ & $0 / 3$ \\
\hline 0 & 15 & 1 & 36 & $7.7-7.9$ & $18 / 18$ & $0 / 3$ & $0 / 3$ \\
\hline 0 & 22 & $11 / 2$ & $43^{\prime}$ & $8.0-8.2$ & $18 / 18$ & $0 / 3$ & $0 / 3$ \\
\hline 0 & 29 & 2 & -- & $7.8-8.0$ & $18 / 18$ & $0 / 3$ & $0 / 3$ \\
\hline 0.1 & 14 & $1 / 2$ & 8 & $6.9-7.1$ & $6 / 15$ & $0 / 3$ & $0 / 3$ \\
\hline 0.1 & 22 & $3 / 4$ & 4 & $7.3-7.9$ & $13 / 18$ & $0 / 3$ & $0 / 3$ \\
\hline 0.1 & 29 & 1 & 12 & $7.0-7.8$ & $11 / 12$ & $0 / 3$ & $0 / 3$ \\
\hline 0.1 & 46 & $11 / 2$ & 21 & $6.7-8.3$ & $18 / 18$ & $0 / 3$ & $0 / 3$ \\
\hline 0.1 & 60 & 2 & - & $6.7-8.1$ & --- & $0 / 3$ & $0 / 3$ \\
\hline 0.2 & 18 & $1 / 2$ & 7.8 & $6.4-7.3$ & $16 / 18$ & $0 / 3$ & $0 / 3$ \\
\hline 0.2 & 27 & $3 / 4$ & 1.7 & $6.4-8.0$ & $11 / 15$ & $0 / 3$ & $0 / 3$ \\
\hline 0.2 & 36 & 1 & 7.0 & $7.1-8.1$ & $15 / 15$ & $0 / 3$ & $0 / 3$ \\
\hline 0.2 & 54 & $11 / 2$ & - & $6.8-8.2$ & $18 / 18$ & $0 / 3$ & $0 / 3$ \\
\hline 0.2 & 80 & 2 & 12 & $6.8-8.3$ & -- & $0 / 3$ & $0 / 3$ \\
\hline
\end{tabular}

1 Untrypsinized.

2 Trypsintzed. 
Table 17-8

Toxin production in haddock inoculated wtth $10^{6}$ spores per gram untrradiated and Irradiated stored at $40 \mathrm{~F}$. Spores produced at $85 \mathrm{~F}$.

\begin{tabular}{|c|c|c|c|c|c|c|c|}
\hline Irr. & Inc. & $x$ & Count & $\mathrm{pH}$ & Rejection & \multicolumn{2}{|c|}{ Toxin } \\
\hline Mr. & Days & {[} & $\times 10^{8}$ & & & U1 & $T^{2}$ \\
\hline 0 & 8 & $1 / 2$ & $>5$ & $7.5-7.6$ & $8 / 15$ & $0 / 3$ & $0 / 3$ \\
\hline 0 & 11 & $3 / 4$ & $>5$ & 7.8 & $13 / 15$ & $0 / 3$ & $0 / 3$ \\
\hline 0 & 17 & 1 & 27 & $7.5-8.1$ & $15 / 15$ & $0 / 3$ & $0 / 3$ \\
\hline 0 & 24 & $1 \cdot 1 / 2$ & 31 & $7.7-8.0$ & $18 / 18$ & $0 / 3$ & $0 / 3$ \\
\hline 0 & 34 & 2 & -- & $8.1-8.2$ & $18 / 18$ & $0 / 3$ & $0 / 3$ \\
\hline 0.1 & 19 & $1 / 2$ & 18 & $7.2-7.5$ & $8 / 18$ & $0 / 3$ & $0 / 3$ \\
\hline 0.1 & 28 & $3 / 4$ & 3 & $6.7-7.9$ & $4 / 12$ & $0 / 3$ & $0 / 3$ \\
\hline 0.1 & 39 & 1 & 2.3 & $6.7-8.0$ & $14 / 18$ & $0 / 3$ & $0 / 3$ \\
\hline 0.1 & 60 & $11 / 2$ & - & $7.4-8.2$ & $15 / 15$ & $0 / 3$ & $0 / 3$ \\
\hline 0.1 & 82 & 2 & 7 & $7.5-8.3$ & $18 / 18$ & $0 / 3$ & $0 / 3$ \\
\hline 0.2 & 20 & $1 / 2$ & 3.3 & $6.9-7.5$ & $8 / 18$ & $0 / 3$ & $0 / 3$ \\
\hline 0.2 & 29 & $3 / 4$ & 2.0 & $6.8-7.4$ & $10 / 12$ & $0 / 3$ & $0 / 3$ \\
\hline 0.2 & 40 & 1 & $1 . .9$ & $6.7-8.0$ & $13 / 18$ & $0 / 3$ & $0 / 3$ \\
\hline 0.2 & 60 & $11 / 2$ & 1.0 & $8.1-8.2$ & $15 / 15$ & $0 / 3$ & $0 / 3$ \\
\hline 0.2 & 82 & 2 & 1.0 & $6.7-8.2$ & $15 / 15$ & $0 / 3$ & $0 / 3$ \\
\hline
\end{tabular}

1. Untrypsinized.

2 Trypsintzed. 
Table 17-9

Toxin production in haddock Inoculated with $10^{4}$ spores per gram unirradiated and Irradlated stored at $40 \mathrm{~F}$. Spores produced at $85 \mathrm{~F}$.

\begin{tabular}{|c|c|c|c|c|c|c|c|}
\hline Irr. & Inc. & $\mathbf{x}$ & Count & $\mathrm{pH}$ & Rejection & & \\
\hline Mr. & Days & & $\underline{X 10^{8}}$ & & & $\underline{\mathrm{U1}}$ & $\mathrm{T}^{2}$ \\
\hline 0 & 8 & $1 / 2$ & $>5$ & 7.3 & $6 / 15$ & $0 / 3$ & $0 / 3$ \\
\hline 0 & 11 & $3 / 4$ & $>5$ & $7.5-7.6$ & $14 / 15$ & $0 / 3$ & $0 / 3$ \\
\hline 0 & 17 & 1 & 49 & $8.0-8.1$ & $15 / 15$ & $0 / 3$ & $0 / 3$ \\
\hline 0 & 24 & $11 / 2$ & 39 & $7.8-7.9$ & $18 / 18$ & $0 / 3$ & $0 / 3$ \\
\hline 0 & 34 & 2 & - & $7.8-8.1$ & $18 / 18$ & $0 / 3$ & $0 / 3$ \\
\hline 0.1 & 19 & $1 / 2$ & 5.7 & $6.7-7.2$ & $1 / 18$ & $0 / 3$ & $0 / 3$ \\
\hline 0.1 & 28 & $3 / 4$ & 3.0 & $7.0-7.8$ & $7 / 12$ & $0 / 3$ & $0 / 3$ \\
\hline 0.1 & 39 & 1 & 7.0 & $7.0-7.9$ & $14 / 18$ & $0 / 3$ & $0 / 3$ \\
\hline 0.1 & 60 & $11 / 2$ & - & $6.9-7.9$ & $15 / 15$ & $0 / 3$ & $0 / 2$ \\
\hline 0.1 & 82 & 2 & 7.0 & $7.9-8.3$ & $18 / 18$ & $0 / 3$ & $0 / 3$ \\
\hline 0.2 & 20 & $1 / 2$ & 8.2 & $6.9-7.4$ & $2 / 18$ & $0 / 3$ & $0 / 3$ \\
\hline 0.2 & 29 & $3 / 4$ & 6.0 & $6.3-7.5$ & $9 / 12$ & $0 / 3$ & $0 / 3$ \\
\hline 0.2 & 40 & 1 & 1.0 & $6.5-7.1$ & $14 / 18$ & $0 / 3$ & $0 / 3$ \\
\hline 0.2 & 60 & $11 / 2$ & -- & $8.2-8.5$ & $15 / 15$ & $0 / 3$ & $0 / 3$ \\
\hline 0.2 & 82 & 2 & 1.0 & $7.4-7.9$ & $18 / 18$ & $0 / 3$ & $0 / 3$ \\
\hline
\end{tabular}

1 Untrypsinized.

2 Tryspinized. 
Table 17-10

Toxin production in haddock inoculated with $10^{6}$ spores per gram unirradiated and Irradiated stored at $42 \mathrm{~F}$. Spores produced at $50 \mathrm{~F}$.

\begin{tabular}{|c|c|c|c|c|c|c|c|}
\hline Irr. & Inc. & $\mathbf{x}$ & Count & $\mathrm{pH}$ & Refection & \multicolumn{2}{|c|}{ Toxin } \\
\hline & Days & & & & & 0 & $T^{2}$ \\
\hline 0 & 9 & $3 / 4$ & 30 & $7.7-7.9$ & $11 / 12$ & $0 / 3$ & $0 / 3$ \\
\hline 0 & 15 & 1 & $44:$ & $7.8-7.9$ & $12 / 12$ & $0 / 3$ & $0 / 3$ \\
\hline 0 & 21 & $11 / 2$ & 37 & $8.0-8.2$ & $18 / 18$ & $0 / 3$ & $0 / 3$ \\
\hline 0 & 30 & 2 & 33 & -- & -- & $0 / 3$ & $0 / 3$ \\
\hline 0.1 & 21 & $3 / 4$ & 12 & $7.6-7.9$ & $13 / 18$ & $0 / 3$ & $0 / 3$ \\
\hline 0.1 & 31 & 1 & 9 & $7.9-8.2$ & $11 / 12$ & $0 / 3$ & $0 / 3$ \\
\hline 0.1 & 45 & $11 / 2$ & -- & $7.9-8.0$ & $18 / 18$ & $0 / 3$ & $0 / 3$ \\
\hline 0.1 & 60 & 2 & - & $8.0-8.2$ & $15 / 15$ & $0 / 3$ & $0 / 3$ \\
\hline 0.2 & 27 & $3 / 4$ & 6.4 & $7.7-8.0$ & $9 / 15$ & $0 / 3$ & $0 / 3$ \\
\hline 0.2 & 35 & 1 & 2.4 & $8.1-8.2$ & $12 / 15$ & $0 / 3$ & $0 / 3$ \\
\hline 0.2 & 55 & $11 / 2$ & 12 & $8.1-8.3$ & $18 / 18$ & $0 / 3$ & $0 / 3$ \\
\hline 0.2 & 72 & 2 & -- & -- & $18 / 18$ & $0 / 3$ & $0 / 3$ \\
\hline
\end{tabular}

1 Untrypsinized.

2 Trypsintzed. 
Table 17-11

Toxin production in haddock inoculated with $10^{4}$ spores per gram unirradiated and Irradlated stored at $42 \mathrm{~F}$. Spores produced at $50 \mathrm{~F}$.

\begin{tabular}{|c|c|c|c|c|c|c|c|}
\hline Irr. & Inc. & $\mathbf{x}$ & Count & $\mathrm{pH}$ & Rejection & \multicolumn{2}{|c|}{ Toxin } \\
\hline Mr. & Days & & $\times 10^{8}$ & & & $U^{I}$ & $\underline{T}^{2}$ \\
\hline 0 & 9 & $3 / 4$ & 18 & $7.5-7.7$ & $9 / 12$ & $0 / 3$ & $0 / 3$ \\
\hline 0 & 15 & 1 & 54 & $7.6-7.8$ & $12 / 12$ & $0 / 3$ & $0 / 3$ \\
\hline 0 & 21 & $11 / 2$ & 35 & $7.8-8.0$ & $18 / 18$ & $0 / 3$ & $0 / 3$ \\
\hline 0 & 30 & 2 & 25 & $-\infty$ & $-\infty$ & $0 / 3$ & $0 / 3$ \\
\hline 0.1 & 21 & $3 / 4$ & 13 & $7.2-7.9$ & $8 / 18$ & $0 / 3$ & $0 / 3$ \\
\hline 0.1 & 31 & 1 & 9.2 & $7.9-8.0$ & $11 / 12$ & $0 / 3$ & $0 / 3$ \\
\hline 0.1 & 45 & $11 / 2$ & 18 & $7.9-8.0$ & $18 / 18$ & $0 / 3$ & $0 / 3$ \\
\hline 0.1 & 60 & 2 & -- & $7.7-8.0$ & $15 / 15$ & $0 / 3$ & $0 / 3$ \\
\hline 0.2 & 27 & $3 / 4$ & 6.4 & $7.3-7.8$ & $13 / 15$ & $0 / 3$ & $0 / 3$ \\
\hline 0.2 & 35 & 1 & 2.4 & $8.0-8.2$ & $14 / 15$ & $0 / 3$ & $0 / 3$ \\
\hline 0.2 & 55 & $11 / 2$ & 14 & $8.0-8.4$ & $18 / 18$ & $0 / 3$ & $0 / 3$ \\
\hline 0.2 & 72 & 2 & -- & -- & $18 / 18$ & $0 / 3$ & $0 / 3$ \\
\hline
\end{tabular}

1 Untrypsinized.

2 Trypsinized. 
Table 17-12

Toxin production in haddock inoculated with $10^{6}$ spores per gram unirradiated and Irradiated stored at $40 \mathrm{~F}$. Spores produced at $50 \mathrm{~F}$.

\begin{tabular}{|c|c|c|c|c|c|c|c|}
\hline Irr. & Inc. & $\mathrm{X}$ & Count & $\mathrm{pH}$ & Rejection & \multicolumn{2}{|c|}{ Toxin } \\
\hline Mr. & Days & & $\underline{\times 10^{8}}$ & & & $\mathrm{UI}$ & $\mathrm{T}^{2}$ \\
\hline 0 & 9 & $3 / 4$ & 22 & $7.6-7.7$ & $9 / 12$ & $0 / 3$ & $0 / 3$ \\
\hline 0 & 16 & 1 & 58 & $7.7-8.0$ & $9 / 9$ & $0 / 3$ & $0 / 3$ \\
\hline 0 & 26 & $11 / 2$ & 36 & $7.9-8.1$ & $18 / 18$ & $0 / 3$ & $0 / 3$ \\
\hline 0 & 34 & 2 & 21 & $7.8-8.2$ & $18 / 18$ & $0 / 3$ & $0 / 3$ \\
\hline 0.1 & 31 & $3 / 4$ & 9 & $7.8-8.1$ & $9 / 12$ & $0 / 3$ & $0 / 3$ \\
\hline 0.1 & 39 & 1 & - & $7.8-8.0$ & $18 / 18$ & $0 / 3$ & $0 / 3$ \\
\hline 0.1 & 60 & $11 / 2$ & -- & $8.0-8.2$ & $15 / 15$ & $0 / 3$ & $0 / 3$ \\
\hline 0.1 & 80 & 2 & -- & --- & --- & $0 / 3$ & $0 / 3$ \\
\hline 0.2 & 31 & $3 / 4$ & 18 & $7.6-8.1$ & $8 / 12$ & $0 / 3$ & $0 / 3$ \\
\hline 0.2 & 40 & 1 & - & $7.7-8.0$ & $8 / 12$ & $0 / 3$ & $0 / 3$ \\
\hline 0.2 & 60 & $11 / 2$ & -- & $8.2-8.3$ & $13 / 15$ & $0 / 3$ & $0 / 3$ \\
\hline 0.2 & 80 & 2 & -- & -- & $18 / 18$ & $0 / 3$ & $0 / 3$ \\
\hline
\end{tabular}

1 Untrypsinized.

2 Trypsintzed. 
Table 17-13

Toxin production in haddock inoculated with $10^{4}$ spores per gram unirradiated and Irradiated stored at $40 \mathrm{~F}$. Spores produced at $50 \mathrm{~F}$.

\begin{tabular}{|c|c|c|c|c|c|c|c|}
\hline Irr. & Inc. & $X$ & Count & $\mathrm{pH}$ & Rejection & & \\
\hline Mr. & Days & $\longrightarrow$ & $\times 10^{8}$ & & & $\underline{\mathrm{UI}}$ & $\underline{T^{2}}$ \\
\hline 0 & 9 & $3 / 4$ & 16.5 & $7.5-7.7$ & $9 / 12$ & $0 / 3$ & $0 / 3$ \\
\hline 0 & 16 & 1 & 45 & $7.7-8.0$ & $9 / 9$ & $0 / 3$ & $0 / 3$ \\
\hline 0 & 26 & $11 / 2$ & 30 & $7.8-8.1$ & $18 / 18$ & $0 / 3$ & $0 / 3$ \\
\hline 0 & 34 & 2 & 31 & $8.0-8.1$ & $18 / 18$ & $0 / 3$ & $0 / 3$ \\
\hline 0.1 & 31 & $3 / 4$ & 9 & $7.2-8.1$ & $9 / 12$ & $0 / 3$ & $0 / 3$ \\
\hline 0.1 & 39 & 1 & - & $7.7-8.0$ & $17 / 18$ & $0 / 3$ & $0 / 3$ \\
\hline 0.1 & 60 & $11 / 2$ & - & $8.1-8.3$ & $15 / 15$ & $0 / 3$ & $0 / 3$ \\
\hline 0.1 & 80 & 2 & - & -- & $\rightarrow-$ & $0 / 3$ & $0 / 3$ \\
\hline 0.2 & 31 & $3 / 4$ & 18 & $8.0-8.1$ & $5 / 12$ & $0 / 3$ & $0 / 3$ \\
\hline 0.2 & 40 & 1 & -- & $7.4-8.1$ & $11 / 12$ & $0 / 3$ & $0 / 3$ \\
\hline 0.2 & 60 & $11 / 2$ & - & $7.9-8.2$ & $15 / 15$ & $0 / 3$ & $0 / 3$ \\
\hline 0.2 & 80 & 2 & - & -- & $18 / 18$ & $0 / 3$ & $0 / 3$ \\
\hline
\end{tabular}

1 Untrypsinized.

2 Trypsintzed. 
Table 17-14

Summary of toxin assays in haddock inoculated with Type E Beluga spores produced at $85 \mathrm{~F}$, unirradiated and irradiated stored at either $50 \mathrm{~F}$ or $46 \mathrm{~F}$.

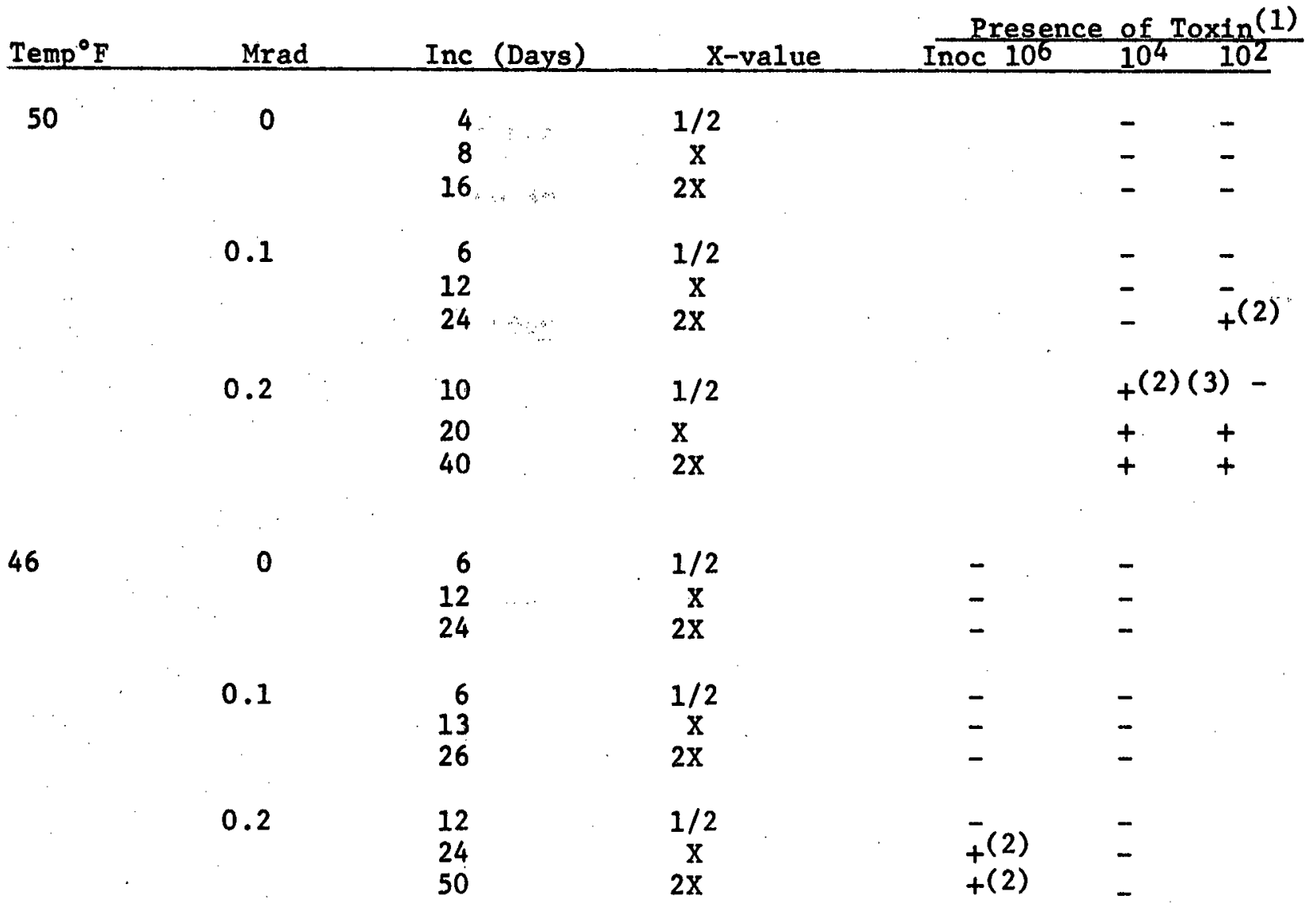

(1) + Toxin detectable; no detectable toxin.

(2) Toxin in 1 out of 3 replicate samples.

(3) Toxin only detectable after trypsin digestion. 
Table 17-15

Summary of toxin assays in haddock inoculated with Type $E$ Beluga spores produced at $85 \mathrm{~F}$, unirradiated and irradiated stored at $42 \mathrm{~F}$.

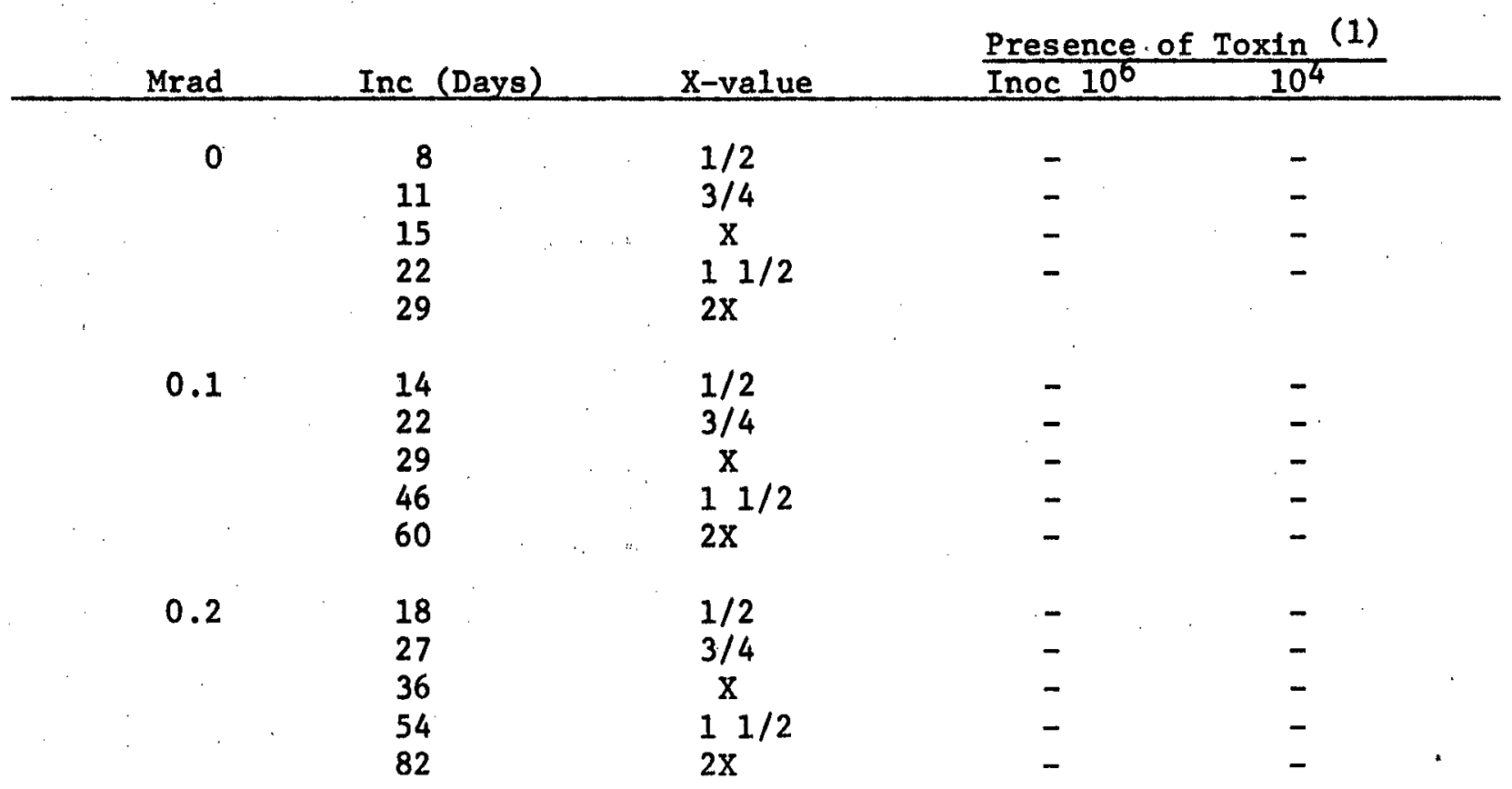

(1) + toxin detectable; no toxin detectable. 
Table 17-16

Summary of toxin assays in haddock inoculated with Type E Beluga spores produced at $85 \mathrm{~F}$, unirradiated and irradiated stored at $40 \mathrm{~F}$.

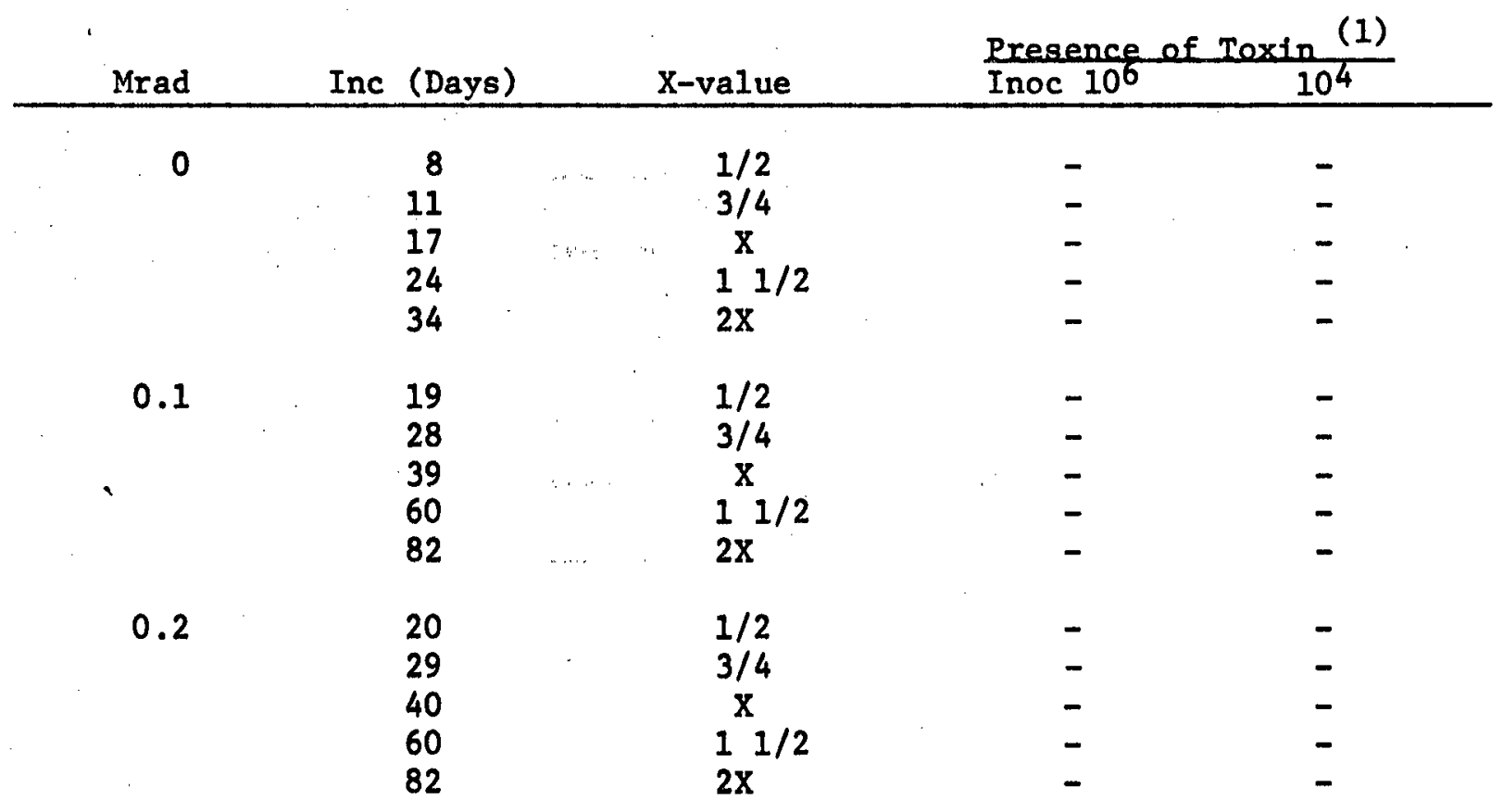

(1) + toxin detectable; no toxin detectable. 
Table 17-17

Summary of toxin assays in haddock inoculated with Type E Beluga spores produced at $50 \mathrm{~F}$, unirradiated and irradiated stored at $42 \mathrm{~F}$ or $40 \mathrm{~F}$.

\begin{tabular}{|c|c|c|c|c|c|c|}
\hline \multirow{2}{*}{$\operatorname{Temp}^{\circ} \mathrm{F}$} & \multirow[b]{2}{*}{ Mrad } & \multirow[b]{2}{*}{ Inoc } & \multirow[b]{2}{*}{ (Days) } & \multirow[b]{2}{*}{ X-value } & \multicolumn{2}{|c|}{ Presence of Toxin (1) } \\
\hline & & & & & Inoc 106 & $10^{4}$ \\
\hline \multirow[t]{8}{*}{42} & 0 & 9. & & $3 / 4$ & - & - \\
\hline & & 15 & & $\mathrm{X}$ & - & - \\
\hline & & 21 & & $11 / 2$ & - & - \\
\hline & & 30 & & $2 \mathrm{X}$ & - & - \\
\hline & 0.1 & 21 & & $3 / 4$ & - & - \\
\hline & & 31 & & $\mathrm{X}$ & - & - \\
\hline & & 45 & & $11 / 2$ & - & - \\
\hline & & 60 & & $2 \mathrm{X}$ & - & - \\
\hline & 0.2 & 27. & & $3 / 4$ & - & - \\
\hline & & 35 & & $\mathrm{x}$ & - & - \\
\hline & & 55 & & $11 / 2$ & - & - \\
\hline & & 72 & & $2 \mathrm{x}$ & - & - \\
\hline \multirow[t]{12}{*}{40} & 0 & 9 & & $3 / 4$ & - & - \\
\hline & & 16 & & $\mathrm{X}$ & - & - \\
\hline & & 26 & & $11 / 2$ & - & - \\
\hline & & 34 & & $2 \mathrm{X}$ & - & - \\
\hline & 0.1 & 31 & & $3 / 4$ & - & - \\
\hline & & 39 & & $\mathrm{X}$ & - & - \\
\hline & & 60 & & $11 / 2$ & - & - \\
\hline & & 80 & & $2 \mathrm{X}$ & - & - \\
\hline & 0.2 & 31 & & $3 / 4$ & - & - \\
\hline & & 40 & & $\mathrm{X}$ & - & - \\
\hline & & 60 & & $11 / 2$ & - & - \\
\hline & & 80 & & $2 \mathrm{X}$ & - & - \\
\hline
\end{tabular}

(1) + toxin detectable; - no toxin detectable. 